WSRC-RP- $-90-421$

DE9 1000507

W SR C-RP- $90-421$

Distribution Category: UC.702

Key Words:

Saltstone

Technetium

Plants

Lysimeters

\title{
LYSIMETER STUDY OF VEGETATIVE UPTAKE FROM SALTSTONE
}

C. E. Murphy, Jr.

Approved by

D. B. Moore, Manager

Environmental Sciences

D. B. Moore, Manager

Authorized Derivative Classifier

Publication Date: June 8, 1990

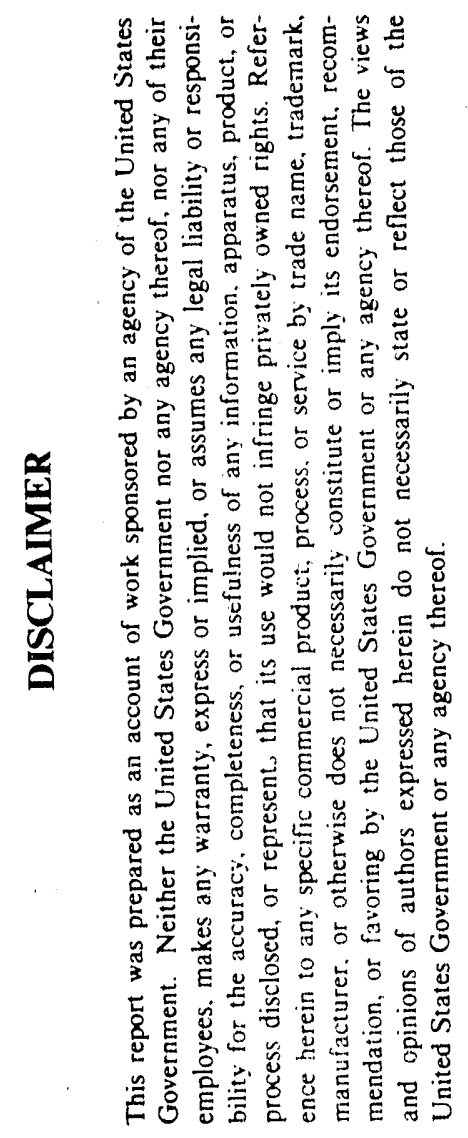

Westinghouse Savannah River Company

Savannah River Site

Aiken, SC 29808

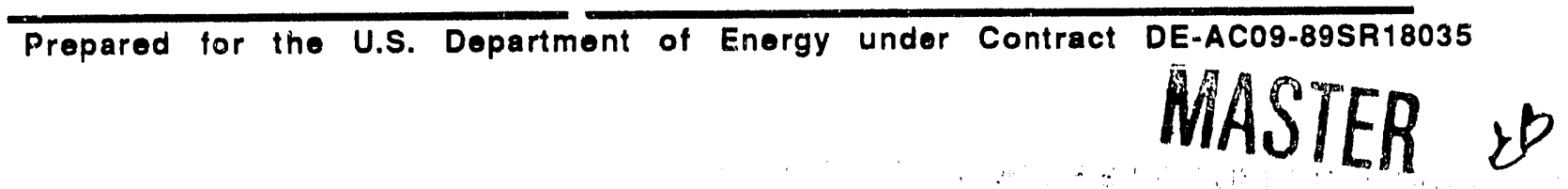


At the Savannah River Site, liquid, low-level nuclear waste will be disposed of by incorporationg the waste in concrete, a wasteform called saltstone. Saltstone monoliths will then be buried in the earth. To study the potential uptake of radionuclides by trees and other plants growing in the soil in the area containing buried saltstone, a lysimeter study has been in progress since 1984. Thirty two lysimeters were designed, constructed, and filled with soil. Saltstone samples, containing the liquid, low-level supernate from the tank 50 in-tank precipitation demonstration, were buried in some of the lysimeters. Other lysimeters, not containing saltstone, were used as controls. Crops, grass, and trees were planted in the lysimeters and sampled periodically to determine radionuclide concentrations. Water samples were also collected from the lysimeter sumps and analyzed for radionuclide content. This report documents the results of vegetative and lysimeter sump water measurements from the beginning of the project in November of 1984 through September of 1989.

Only Tc-99 and Cs-137 could be detected at elevated concentrations in the vegetation. The results indicate that the formulation of saltstone used in this experiment will allow uptake of Tc-99 into vegetation that penetrates into the region where the saltstone is buried. The uptake appears to be related to release of the Tc-99 from the saltstone into the soil water where it is taken up by the plants. The amount of Tc-99 uptake was not consistently related to the depth of burial of the saltstone. Blocks of saltstone purposely broken at the start of the experiment did release greater amounts of nitrate, sulfate, and Tc-99 into the sump water. However, uptake of Tc-99 concentration in the vegetation was not significantly greater in the broken block lysimeters than in the other lysimeters containing saltstone.

There was some indication that small amounts of Cs-137 was taken up from the release of this radionuclide from the buricd saltstone blocks. The Cs-137 concentration differences between the plants grown in control and saltstone lysimeters was very small and the consequences of this uptake are likewise likely to be small.

Vegetative uptake factors were calculated for uptake of Tc-99 from soil water. The results were very similar for the vegetative parts of all of the species grown $(0.167-0.376[\mathrm{pCi} / \mathrm{gm}] /[\mathrm{pCi} / \mathrm{L}])$. The uptake factor calculated for the seeds of crops was less by a factor of 100 than the uptake factor for vegetative parts. 


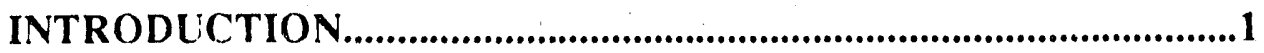

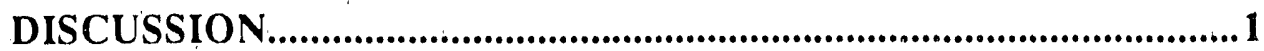

Experimental Design ................................................... 1

Lysimeter Design. ................................................................4

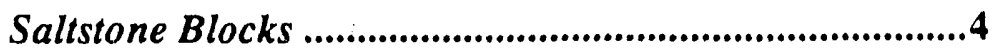

Lysimeter Soil ............................................................... 6

Vegetative Management..........................................................8

Crops ........................................................................... 8

Pine Trees ......................................................................9

Bermuda Grass ........................................................ 10

Data Collection ...................................................................... 10

Vegetation Sampling and Analysis ............................... 10

Soil Sampling and Analysis ........................................ 13

Water Sampling and Analysis ..........................................13

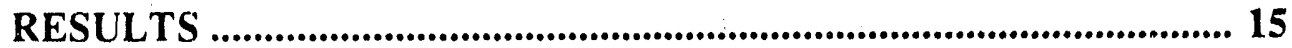

Statistical Analysis of Data ...................................................... 15

Vegetation Uptake of Radionuclides and Chemical Elements ...........................................................................16

Technetium-99 .............................................................18

Cesium-137 ............................................................................. 18 
Radionuclide and Chemical Concentrations in

L ysimeter Sump Water ....................................................... 21

Nitrate ........................................................................

Sulfate ................................................................................. 22

Conductivity ...........................................................................25

Metals ..................................................................................... 26

Technetium-99 ...................................................................28

Concentration Factors for Tc-99 Uptake from

Lysimeter Soil Water .......................................................... 32

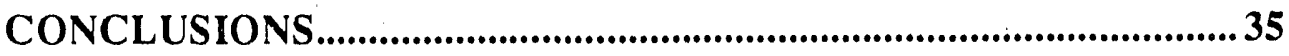

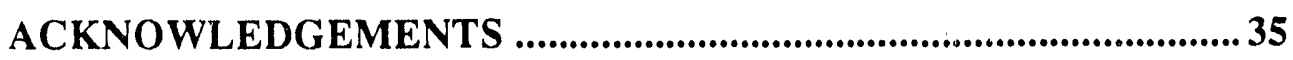

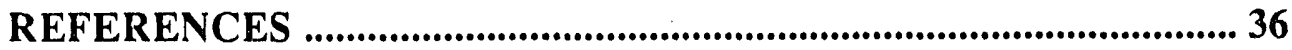

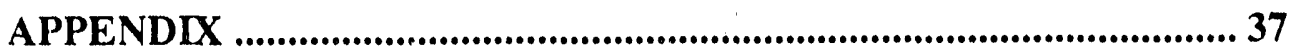




\section{LIST OF FIGURES}

1 Layout of Lysimeter Study Area at the Low Level Burial Ground ....................... 3

2 Crossectional View of a Saltstone Lysimeter as Used in the Vegetation Uptake Study ...................................................................................... 5

3 Diagram of Schedule for Vegetation Management and Sampling........................... 9

4 Technetium-99 Concentrations in Grass .......................................................... 19

5 Technetium-99 Concentration in Trees .......................................................... 19

6 Techetium-99 Concentration in Crop Vegetative Parts ....................................... 20

7 Techetium-99 Concentration in Crop Seeds ...................................................... 20

8 Cesium-137 Concentrations in Grass ................................................................. 21

9 Nitrate Concentration in Sump Water of Grass Lysimeters ................................... 24

10 Nitrate Concentration in Sump Water of Tree Lysimeters .................................. 24

11 Nitrate Concentration in Sump Water of Crop Lysimeters .................................. 25

12 Concentration of Sulfate in Sump Water of Grass Containing Lysimeters ........................................................................................26

13 Comparison of Conductivity and Nitrate Concentration of Sump Water for All Lysimeters............................................................................227

14 The Concentration of Tc-99 in the Sump Water of the Grass

Lysimeters ....................................................................................... 28

15 The Concentration of Tc-99 in the Sump Water of the Tree Lysimeters

16 The Concentration of Tc-99 in the Sump Water of the Crop Lysimeters

17 Comparison of Tc-99 Concentrations in Sump Water and Vegetation in the Grass Lysimeters

18 Comparison of Tc-99 Concentrations in Sump Water and Vegetation in the Tree Lysimeters 
19 Comparison of Tc-99 Concentrations in Sump Water and Vegetation in the Crop Lysimeters ..................................................................................... 31

20 Concentration Uptake Factors for Tc-99 from Sump Water to Grass ................... 32

21 Concentration Uptake Factors for Tc-99 from Sump Water to Trees .....................33

22 Concentration Uptake Factors for Tc-99 from Sump Water to Vegetation and Seeds of Crops ............................................................................................32

viii 
1 Experimental Design for Saltstone Vegetation Study ........................................

2 Chemical and Radionuclide Composition of Decontaminated Supernate and Blended Cement...................................................................

3 Nonradioactive Sump Water Analysis Procedures ............................................8

4 Analysis of Variance Probabilities of an Effect of Treatment for Vegetation Concentrations ....................................................................... 17

5 Analysis of Variance Probabilities for an Effect of Treatment for Sump Water ConceNtrations ................................................................... 23

6 Mean ratios of Tc-99 Activity in Vegetation versus Lysimeter Sump Water for Different Vegetation Types in Units of $(\mathbf{p C i} / \mathbf{g m}) /(\mathbf{p C i} / \mathrm{L})$

A.1 Averge Vegetation Radionuclide and Elemental Concentrations in Bermuda Grass

A.2 Average Vegetation Radionuclide and Elemental Concentrations in Trees

A.3 Average Vegetation Radionuclide and Elemental Concentrations in Crops Vegetative Parts

A.4 Average Radionuclide and Elemental Concentrations in Crop Seed

A.5 Average Nonradioactive Lysimter Sump Water Concentrations for

Grass Lysimeters :

A.6 Average Nonradioactive Lysimter Sump Water Concentrations for Tree Lysimeters

A.7 Average Nonradioactive Lysimter Sump Water Concentrations for Crop Lysimeters

A.8 Averge Radioactive Isotope Concentrations in Grass Lysimeter Sump Water . .45

A.9 Averge Radioactive Isotope Concentrations in Tree Lysimeter Sump Water

A.10 Averge Radioactive Isotope Concentrations in Crop Lysimeter

Sump Water

$$
\mathrm{ix} / \mathrm{X}
$$




\section{LYSIMETER STUDY OF VEGETATIVE UPTAKE FROM SALTSTONE}

\section{INTRODUCTION}

At the Savannah River Site, the Defense Waste Processing Facility will vitrify high-level radioactive defense waste for shipment to a federal repository. During waste processing. approximately 25 million gallons of salt solution will be decontaminated. This will result in 100 million gallons of lowlevel waste salt solution which will be immobilized in saltstone. Saltstone is a solidified mixture of the low-level radioactive salt solution, fly ash, and cement. The saltstone will be disposed of in an engineered landfill.

Beginning in 1984, the Savannah River Laboratory's Environmental Sciences Section designed, installed, and operated a lysimeter test facility to obtain data on the vegetative uptake of radionuclides from the buried saltstone. Details of the design and installation phases of the project can be found in Johnson (1985). This report documents the results of vegetation and sump water measurements from the installation of the lysimeters, from November of 1984 through September 1989.

The Saltstone Vegetative Uptake Lysimeter Facility is located at the SRS burial ground. The lysimeter facility comprises 32 lysimeters. These lysimeters are large, cylindrical, open-topped tanks, 6 feet in diameter and 6 to 10 feet in depth. The tanks are buried to ground level and filled with soil. Saltstone bricks are buried within the lysimeters. The depth of burial and condition of the blocks varies among the lysimeters. Several different types of vegetation are grown in the lysimeters. The vegetation is periodically sampled and analyzed for radionuclide content. Water collected in the sump at the base of each lysimeter is withdrawn for analysis and disposal.

\section{DISCUSSION}

\section{Experimental Design}

The experimental design is based on what is thought to be a worst case scenario for future use of the burial site. The assumptions are: 1) the soil cover over the saltstone will erode to the point that plant roots w'ill reach the saltstone, and 2) the area will become a family farm where the family will grow and consume crops and other products from the farm. Three significant variables were derived from this scenario: 1) depth of saltstone from the surface, 2) vegetation type, and 3) saltstone structural integrity (crumbling saltstone versus unbroken saltstone). The experiment was designed to include combinations of these variables in order to learn the magnitude of their influence on vegetative uptake.

The experimental design is shown in Table 1. There are fifteen different test conditions, each condition representing a different combination of saltstone depth, vegetation type, and condition of the saltstone block. With the exception of one of the control lysimeters which was used for another project, each condition tested was replicated once. Only 27 of the original 32 lysimeters were used in the experiment. In addition to the one lysimeter utilized for another project, the original design called for the saltstone in two of the lysimeters to be maintained below a perched water table in the lysimeter. However, rainfall was not great enough during the years of the experiment to maintain the water level above the saltstone and these lysimeters were never used in the experiment. An additional two lysimeters 
Table 1. Experimental Design for Saltstone Vegetation Study.

\section{Saltstone Block Depth}

\begin{tabular}{|c|c|c|c|c|c|c|}
\hline Vegetation & Cuntrol & 6 inch & 18 inch & 36 inch & 54 inch & $\begin{array}{l}\text { Broken Block } \\
\text { (@ } 12 \text { inches) }\end{array}$ \\
\hline Crop & $\mathrm{x}$ & 0 & $\mathrm{x}$ & $\mathrm{x}$ & o & $\mathrm{x}$ \\
\hline Grass & $X$ & $x$ & $\mathrm{X}$ & $\mathrm{X}$ & $\mathrm{x}$ & $\mathrm{X}$ \\
\hline Trees & $\mathrm{X}^{1}$ & O & O & $\mathrm{X}$ & $\mathrm{x}$ & $\mathrm{X}$ \\
\hline
\end{tabular}

1 No replicate of this lysimeter type.

$\mathrm{X}=$ unsaturated lysimeter

$\mathrm{O}=$ no lysimeter for the condition

were to be used for a study of the effect of ants on the buried saltstone. This study was abandoned when it became clear that the ants could not be contained in the lysimeters. The layout of the 32 lysimeters is shown in Figure 1.

The vegetation types selected for this experiment are: loblolly pine trees, coastal Bermuda grass, and a rotation of locally grown crops, corn, wheat, and soybeans. These vegetation types were selected because they are common in the SRS area and represent a mixture of shallow-rooted and deep-rooted crops, perennials, and annuals.

The crops are grown in eight lysimeters, two replicates of four conditions: whole, structurally sound saltstone buried at 18 and 36 inches, broken saltstone buried at 12 inches, and control lysimeters with no saltstone. The saltstone blocks in the broken block lysimeters were cracked with a sledge hammer after being placed into the lysimeter. Bermuda grass is grown in twelve lysimeters containing saltstone blocks buried at $6,18,36$, and 54 inches from the surface, broken saltstone blocks at 1 ? inches, and control lysimeters. There is a total of twelve grass containing lysimeters including two of each condition. Trees are grown in lysimeters containing saltstone at 36 and 54 inches, broken saltstone at 12 inches, and in a single control lysimeter. With two replicates of each condition of the tree lysimeters, except for the control, a total of severi lysimeters were used. However, there was high mortality of trees planted in the broken block lysimeter and even after repeated plantings one lysimeter never contained a tree and the other had a succession of short lived trees(less than one to three years). 


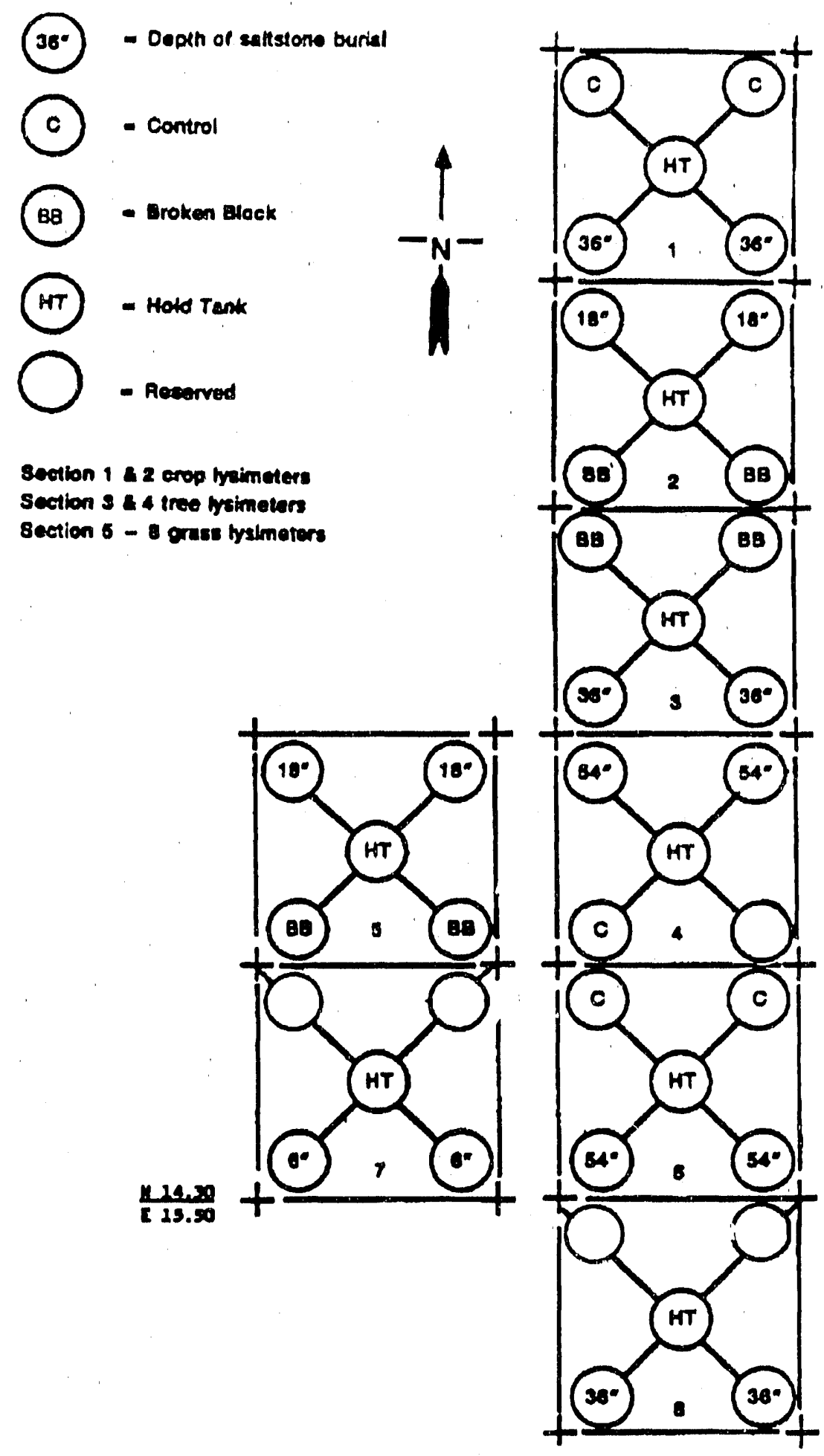

Figure 1. Layout of Lysimeter Study Area at the Low Level Burial Ground. 


\section{Lysimeter Design}

A detailed discussion of lysimeter design can be found in Johnson'. At SRS, lysimeters have become an established technology for studying migration of constituents of buried waste in soil..$^{2.3}$ The advantage of lysimeter use in studies of waste isolation systems is that near natural concitions can be investigated while protecting the surrounding environment.

The lysimeters for this experiment are upright, cylindrical tanks, 6 feet in diameter, with a sealed, flat, level bottom and an open top. They are constructed of 3/16-inch galvanized steel with welded seams (Figure 2). After fabrication each tank is lined with a 20-mil PVC liner. The PVC liner provides extra protection against water leaking into or out of the tank and prevents tank materials and corrosion products from interfering with groundwater chemical analyses.

The lysimeters were set on concrete slabs at the bottom of eight foot diameter holes bored into the ground. The space between the lysimeter and the ground was filled with concrete to within one foot of the surface and filled the rest of the way to the surface with soil. The lysimeters were filled with soil and other material, from bottom to top, as follows: one foot of 2-inch gravel, three and three quarters feet of subsoil, a 3-inch layer of saltstone blocks, and cover soil to the top of the lysimeter. The lysimeters were constructed so that the saltstone blocks were buried five and one quarter feet above the bottom of the lysimeter and enough depth remained for the soil called for in the experimental design. For example, the lysimeters with saltstone buried at six inches were six feet deep while the lysimeters with saltstone buried at 54 inches were ten feet deep. The top 6 inches of the lysimeter tank are unfilled, creating a 6-inch rim above ground that prevented surface water from flowing into or out of the lysimeters. The top one foot of cover soil ( 6 inches for the 6 -inch cover-soil lysimeters)was filled with topsoil; the remainder is subsoil.

Each lysimeter is fitted with a standpipe for removing water from the gravel sump of the lysimeter. The standpipe is a 12 -inch-diameter corrugated metal pipe that is installed vertically along the inside of the tank wall, extending to the bottom. The bottom one-foot section that is in the gravel sump zone is perforated, allowing sump water to pass through. A submersible pump suspended in the standpipe removes the water through the top of the standpipe, through an underground PVC pipeline, to a below-grade water collection tank (hold-tank). The PVC piping system includes an aboveground bypass line so that water samples can be collected for chemical analysis. The lysimeters are arranged in eight groups, each group consisting of four lysimeters connected to one centrally located hold-tank.

\section{Saltstone Blocks}

Each lysimeter holds 2.5-cubic-feet of saltstone in the form of nine blocks, each 11 inches wide by 14 inches long by 3 inches thick. The bricks are arranged in a single layer in a three by three, square pattern. This arrangement provides maximum use of the 6-foot-diameter cross section of the lysimeter, thus providing maximum soil-to-waste-to-root contact, while still permitting sufficient drainage around and between the saltstone blocks. 


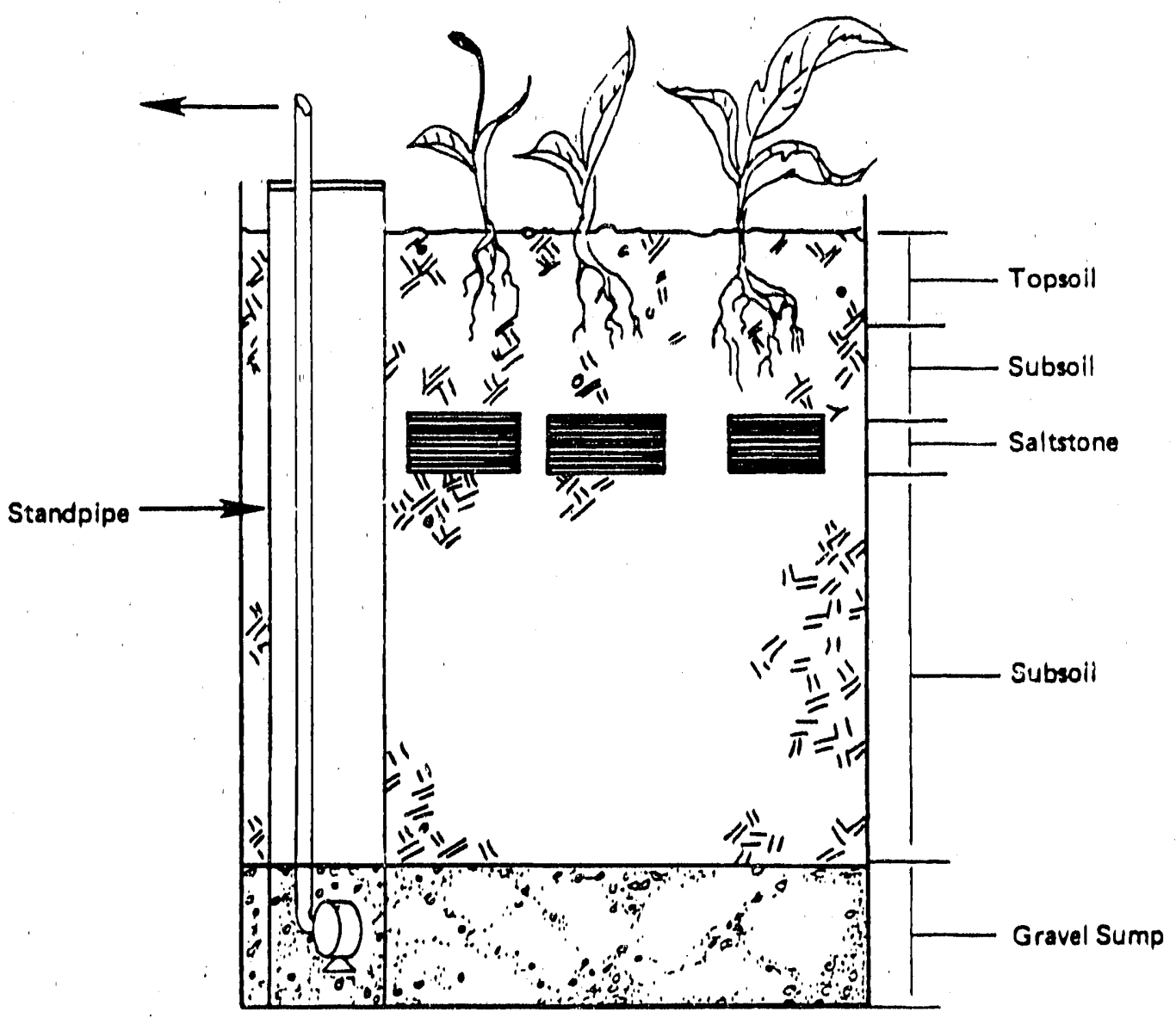

Figure 2. Cross-Sectional View of a Saltstone Lysimeter as Used in the Vegetation Uptake Study. 
The blocks were made from decontaminated radioactive salt solution from Waste Tank 50. A group of nine blocks contains $3 \mathrm{mCi}$ of activity. The composition of the waste solution and the cement used to make the saltstone is given in Table $2 .{ }^{1}$

The saltstone for the blocks was mixed by the same process described in the Tank 24 Saltstone Lysimeter Demonstration. ${ }^{4}$ However, the method of pouring the saltstone mix was modified to provide 80 -gallon batches which were used to fill 250 individual small forms (plastic trays). The filled trays were stacked inside a storage building for curing and storage until the lysimeters were ready for brick placement. During storage, the blocks were inspected monthly' to confirm that curing was proceeding properly.

Samples of the saltstone blocks were subjected to a series of tests to determine how their physical and chemical properties compare to theoretical values and to other saltstone samples. The properties that were determined were: (1) leachability, (2) source terms, (3) x-ray diffraction, and (4) compressive strength. The results of these tests show that the saltstone blocks in the vegetative uptake lysimeters are of yuod quality, and are similar to the saltstone produced in the Tank 24 demonstration and in the laboratory. ${ }^{1,6}$ Differences can be attributed to differences in the methods of preparing samples.

Four samples of saltstone, two from each of two blocks, each approximately $50 \mathrm{gm}$ in weight, were analyzed for major chemical constituents: nitrates, sulfates, sodium, aluminum, calcium, and silicon. The samples were dissolved in acid solutions and analyzed by ion chromatography and plasma-source emission spectrometry.

The calculated composition was obtained by multiplying the known chemical analysis of the Tank 50 salt and the blended cement by their respective weight ratio to total saltstone weight (i.e., $0.42 \mathrm{~g} \mathrm{salt} / \mathrm{g}$ saltstone, and $0.58 \mathrm{~g}$ blended cement/g saltstone ). The weight percentage of nitrates, sulfates, and sodium in saltstone was calculated to be, respectively, 5.4, 0.5, and 4.3. This compares to the measured values of $6.3,1.3$, and 5.8. The respective disagreement is $17 \%$ for nitrate, $160 \%$ for sulfate and $35 \%$ for sodium. Some of the additional sulfate measured may come from the gypsum in the concrete. The weight percentages of constituents derived from the cement are all in good agreement with the calculated values (the error is less than $17 \%$ ).

\section{Lysimeter Soil}

Soil properties will influence both the uptake of radionuclides by vegetation and the movement of radionuclides in the soil water to the lysimeter sumps. The objectives for selecting the soil were: to simulate soil in the area where actual saltstone disposal trenches will be located ( $Z$ Area), to provide sufficient drainage to have sufficient porosity to permit vegetative growth, and to achieve consistency among the lysimeters.

It was determined that Z-Area subsoil would be well represented by burial ground subsoil. Both burial ground and Z-Area subsoils are red-yellow, clay-sands with vertical permeabilities in the range of $10^{-1}$ to $10^{-4} \mathrm{~cm} / \mathrm{sec}$. The burial ground subsoil placed in the lysimeters was obtained from excavations made at the lysimeter site and areas immediately adjacent. An analysis was performed on samples of 
Table 2. Chemical and Radionuclide Compositon of Decontaminated Supernate and Blended Cement.

Decontaminated Supernate

\begin{tabular}{|c|c|c|c|}
\hline Chemical & \% Weight & $\begin{array}{l}\mathrm{nCi} / \mathrm{gm} \text { of } \\
\text { Radionuclide }\end{array}$ & Solution \\
\hline $\mathrm{H}_{2} \mathrm{O}$ & 70 & ${ }^{99} \mathrm{Tc}$ & 35 \\
\hline $\mathrm{NaNO}_{3}$ & 17.7 & ${ }^{106} \mathrm{Ru}$ & 6.6 \\
\hline $\mathrm{Na}_{2} \mathrm{CO}_{3}^{3}$ & 2.1 & ${ }^{106} \mathrm{Rh}$ & 6.6 \\
\hline $\mathrm{NaAl}(\mathrm{O} H)_{4}$ & 2.6 & ${ }^{129} \mathrm{I}$ & - \\
\hline $\mathrm{NaOH}$ & 3.6 & ${ }^{79} \mathrm{Se}$ & $<0.3$ \\
\hline $\mathrm{Na}_{2} \mathrm{SO}_{4}$ & 1.7 & ${ }^{137} \mathrm{Cs}$ & 1.7 \\
\hline $\mathrm{CaSO}_{4}$ & 0.24 & ${ }^{137} \mathrm{~m} \mathrm{Ba}$ & 1.7 \\
\hline $\mathrm{NaCl}^{4}$ & 0.005 & ${ }^{90} \mathrm{Sr}$ & $<0.3$ \\
\hline $\mathrm{NaB}\left(\mathrm{C}_{6} \mathrm{H}_{6}\right)_{4}$ & 0.04 & ${ }^{90} \mathrm{Y}$ & $<0.3$ \\
\hline $\mathrm{NaF} \quad 6 / 4$ & 0.004 & ${ }^{125} \mathrm{Sb}$ & 3.5 \\
\hline $\mathrm{NaSiO}_{3}$ & 0.004 & ${ }^{239} \mathrm{Pu}$ & $<0.38$ \\
\hline $\mathrm{NaNO}_{2}$ & 0.9 & & \\
\hline $\mathrm{Na}_{2} \mathrm{CrO}_{4}$ & 0.006 & & \\
\hline $\mathrm{Na}_{2} \mathrm{MoO}_{4}$ & 0.0004 & & \\
\hline $\mathrm{NaHgO}(\mathrm{O} H)$ & $2 \times 10^{-6}$ & & \\
\hline $\mathrm{NaAg}(\mathrm{OH})_{2}$ & $<1 \times 10^{-7}$ & & \\
\hline
\end{tabular}

Blended Cement

\begin{tabular}{lr} 
Chemical & wt\% \\
\hline & \\
$\mathrm{CaO}$ & 33.2 \\
$\mathrm{SiO}_{2}$ & 34.1 \\
$\mathrm{Al}_{2} \mathrm{O}_{3}$ & 15.1 \\
$\mathrm{Fe}_{2} \mathrm{O}_{3}$ & 6.1 \\
$\mathrm{MgO}^{\mathrm{SO} O}$ & 4.0 \\
$\mathrm{SO}_{3}$ & 2.1 \\
$\mathrm{Na}_{2} \mathrm{O}$ & 1.5
\end{tabular}


the burial ground subsoil before it was placed in the lysimeters to verify that it was uncontaminated. Results showed only natural background activity. ${ }^{1}$

All of the topsoils available were generally similar, loamy sands. Burial ground or other SRS site topsoil could have been used. However, topsoil from Z Area was used in the lysimeters to achieve the best possible simulation of the actual soil conditions under which the saltstone monoliths will be buried.

\section{Vegetation Management}

\section{Crops}

Consistent with the objective of growing vegetation that will provide radionuclide uptake data that can be used to determine the potential dose from DWPF saltstone, standard agricultural practices for the SRS area were followed in growing all crops. Before planting of the first crop, the soil was limed and fertilized with i0-10-10 (N:P:K) and a micronutrient mixture ( $\mathrm{Mg}, \mathrm{Mn}, \mathrm{Zn}, \mathrm{Fe}, \mathrm{Mo}, \mathrm{Cu}$ ). Soybean seeds were sown in July of 1984 and harvested in November of the sarne year. The soybean crop was followed by wheat, planted in December of 1984, and harvested in June of 1985. A second soybean crop was grown between June and November of 1985. The lysimeters were fertilized before each planting and the wheat was top dressed with 10-10-10 fertilizer in March of 1985.

No crops were grown in the spring and summer of 1986. Wheat was planted in December of 1986 and harvested in June of 1987 . The wheat crop was followed with a corn crop, planted in late June and harvested in November of 1987 . During periods between and after cropping, the lysimeters were allowed to grow up in weeds.

Liquid Sevin was applied to the crops on an as-needed basis to control insects, primarily corn earworms. During periods of low rainfall the crop lysimeters w'ere irrigated with domestic water. The usual application was 25 gallons (the equivalent of one-inch of rain) at an average frequency of once per week. Irrigation was necessary only in the summer months and then on only one or two occasions each summer.

Soil amendments to date include the addition of lime and 10-10-10 fertilizer to the Bermuda grass lysimeters and crop lysimeters prior to planting, and a reapplication of 10-10-10 fertilizer to the crop lysimeters mid-way through their growing seasons. An application of a specially-prepared mix of micronutrients was needed for the first soybean crop.

It is recognized that lime and fertilizer will add chemical constituents such as nitrates, mercury, and potassium-40 to the lysimeters. However the control and the saltstone lysimeters has the same fertilizer amendments and differences between the two types of lysimeters should be attributable to the saltstone alone. 


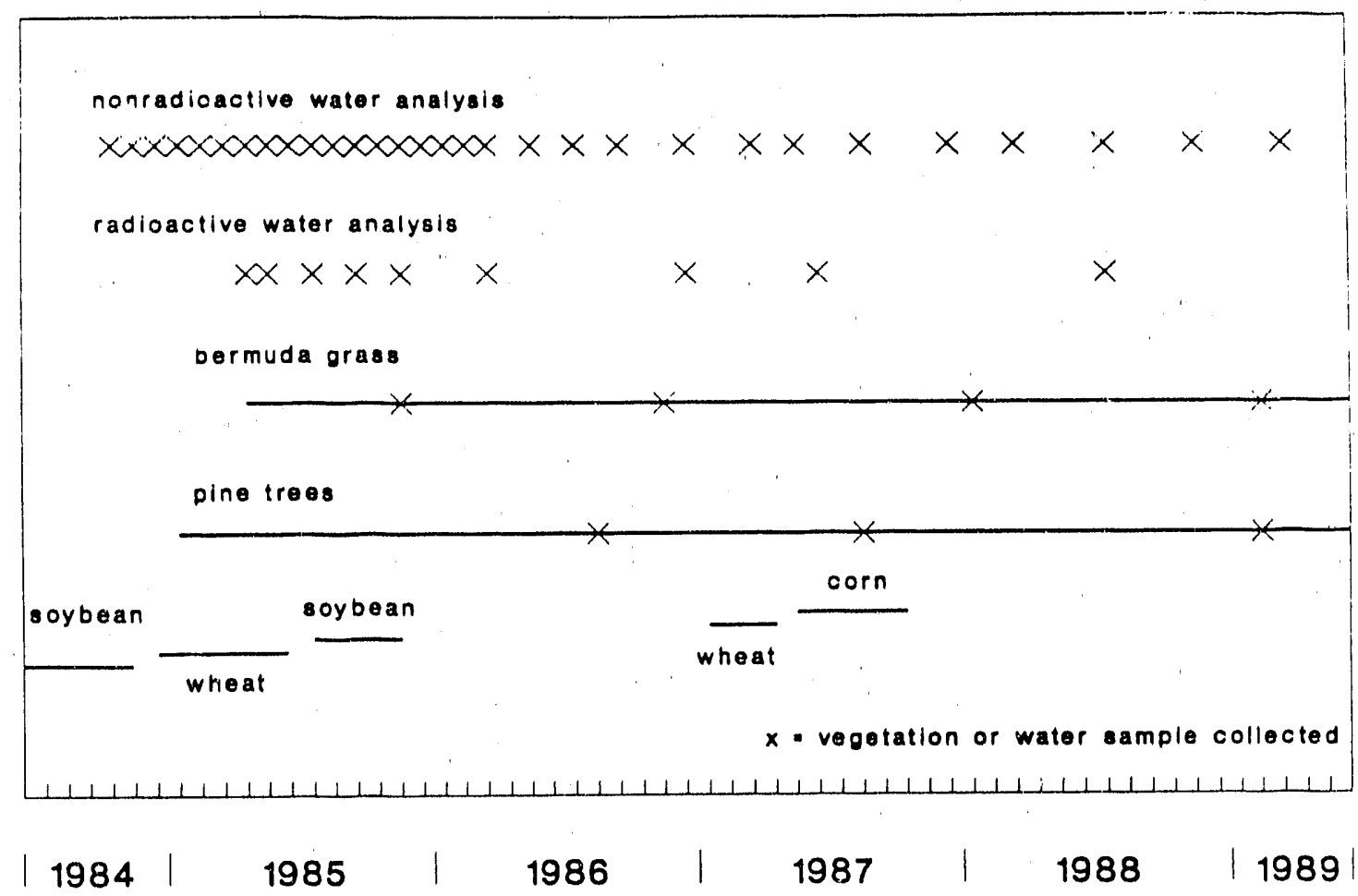

Figure 3. Diagram of Schedule for Vegetation Management and Sampling.

\section{Pine Trees}

Loblolly pine (Pinus taeda, L.) seedlings were planted in January of 1985 . These lysimeters were not limed or fertilized at any time during the experiment. The trees planted in the lysimeters containing broken blocks died within two months of planting. One lysimeter was replanted in March but the seedling died the following summer. It is suspected that death was caused by the high nitrogen concentration around the broken blocks. Pine trees have low nitrogen requirements and relatively low nitrate tolerance. These lysimeters were replanted during the following winter. The tree on one of the lysimeters died within a few months. The tree in the other broker block lysimeter survived and grew after the second planting. However, it suddenly died at the end of the summer of 1990 . 


\section{Bermuda Grass}

Bermuda grass (variety coastal) sprigs were planted in the lysimeters in March of 1985 . The lysimeters were limed and fertilized before planting and fertilized again in July of 1985. It was planned to fertilize the grass each year, the common practice in this locality; however, the grass grew so well that these lysimeters were not fertilized after the first year. The vigor of the grass was so great that matting of the dead grass from each years growth became a problem. The dead grass was removed from the lysimeters each winter after 1986.

\section{Data Collection}

\section{Vegetation Sampling and Analysis}

The vegetation sampling schedule is shown in Figure 3. Crops were sampled at the end of the growing period. When available, $500 \mathrm{gm}$ of leaves/stem material and $500 \mathrm{gm}$ of seed were collected. On some occasions less than $500 \mathrm{gm}$ were available. In this case the total available material was collected. In one instance, there was not enough sample to make all of the analyses. In this case, only the most important analyses were done.

Tree needles were sampled after the growing seasons of 1986,1987, and 1988. The samples contained 500 or more grams of green needles. Sampling was not begun until 1986 because it was feared that the removal of a sample of needles would kill the small seedlings. Loblolly pine trees contain two ages of needles during the summer and only one age of needle between needle fall in the fall and renewed growth in the spring. Summer needle collections were made of second year needles because the current year needles sustain the tree through the winter and it was feared that removing them from the small trees would lead to death. Therefore, the majority of the needles collected in 1986 were grown in 1985, the majority of the needles collected in 1987 were grown in 1986, but the needles collected in the winter of 1989 were grown in 1988. This does not mean that the nuclides date from these periods since many of the mineral constituents of needles are mobile and their concentrations are the result of uptake over their whole life and not just the period of initial growth. However, elements involved in the structural material of the needles are likely to be less mobile and may actually reflect the conditions when the needles were grown.

The bermuda grass grew very rapidly once it was established in the lysimeters and it was possible to collect leaf/stem samples after the $1985,1986,1987$, and 1988 growing seasons. Since the stem and leaf die after frost each year, the material is all grown in the spring and summer before the sample is taken.

Each vegetation sample is analyzed for concentrations of the radionuclides, Tc-99, Sr-90, I-129, $\mathrm{Cs}-137, \mathrm{H}-3, \mathrm{Pu}-238, \mathrm{Pu}-239,240, \mathrm{Ru}-106, \mathrm{Sb}-125$, and the nonradioactive elements, total nitrogen, total sulfur, and total mercury. The analyses were done during 1984 and 1985 by CEP Laboratories, Las Vegas, NM. Later analyses were done by TMA/Norcal of Richmond, California. The following paragraphs provide a short summary of the techniques used by TMA/Norcal in analyzing the vegetation samples. 
The total sample received is homogenized by grinding, milling, breaking up with a mortar and pestle, or other means to insure that representative aliquots can be taken. A measured fraction is taken and dried. A dried weight is obtained to determine percent moisture. From this, an aliquot is taken and ashed for dissolution. The required radiological analyses are performed on aliquots of undried vegetation, dried vegetation, or dissolved vegetation. The form used depends upon the volatility characteristics of the element.

The ash is leached with a nitric acid/hydrogen peroxide solution and the insoluble residue is filtered out. The filter is ashed and dissolved by sequential treatments with $\mathrm{HF} / \mathrm{HNO}_{3}, \mathrm{H}_{3} \mathrm{BO}_{3}, \mathrm{HCl}$, and $\mathrm{HNO}_{3}$. The solution from this cycle is combined with the original leachate to complete the dissolution. Some vegetation ash is more resistant, and if a residue remains, it is treated again (Wessman, et al, 1977). The total dissolved ash aliquot or portions of it, depending upon activity levels, are taken for the sequential separations or specific analyses as described in the following sections.

Cs-137, Sb-125, and Ru-106 are measured by high resolution gamma spectrometry. A $500-\mathrm{mL}$ aliquot of prepared sample is placed in a Marinelli beaker and weighed. If there is a shortage of sample material, other calibrated containers are selected to match the sample. The sample is counted for at least 400 minutes on a high resolution gamma spectrometer. Each sample is counted on one of the 5 high resolution, $\mathrm{Ge}(\mathrm{Li})$ gamma spectrometers which are installed at TMA/Norcal. The spectra are evaluated and quantified by computer analysis. The instruments are calibrated using multi-gamma standard solutions from Amersham/Searle. Single isotope standards are also used. Instrument quality control is performed routinely, according to a schedule.

Tritium is separated from the tissue by azeotropic distillation. An appropriate sized aliquot is taken and ground or pulverized. Toluene is added and an azeotropic distillation is performed. The distillation is run until all water is collected. The total mass of the collected distillate is measured and compared to the \% moisture of the sample to check for completeness. Up to five grams of distillate are taken for counting. An aliquot of distillate is added to a scintillation cocktail and counted on a liquid scintillation counter for 300 minutes. The sample is spiked with a known amount of tritium standard to check the counting efficiency. Results are reported either in terms of grams dry weight of sample or volume of distillate collected.

Technetium-99 samples are homogenized, spiked with Tc-99m tracer, and ashed. The ash, after cooling, is leached with $6 \mathrm{~N} \mathrm{H}_{2} \mathrm{SO}_{4}$ and filtered. Tc (VII) is extracted from the filtrate with tributyl phosphate (TBP). The TBP phase is washed with $6 \mathrm{~N} \mathrm{H}_{2} \mathrm{SO}_{4}$ and then $4 \mathrm{~N} \mathrm{HCl}$. Tc is back extracted with $\mathrm{H}_{2} \mathrm{O}$. Scavenge carriers of $\mathrm{Ag}+, \mathrm{Co}++$, and $\mathrm{Fe}+++$ are added and appropriate precipitations done, each time reserving the supernate solution with the Tc activity. The solution is adjusted to $0.1 \mathrm{~N} \mathrm{HCl}$ and Tc is absorbed on an anion exchange resin column. Impurities are removed in a $0.1 \mathrm{~N} \mathrm{HCl}$ wash, the Tc is eluted with warm $8 \mathrm{~N} \mathrm{HNO}_{3}$. The solution is boiled down and electroplated onto a one inch stainless steel disc. With each run, two standards of the $\mathrm{Tc}-99 \mathrm{~m}$ tracer are counted on a $\mathrm{Ge}(\mathrm{Li})$ gamma spectrometer to calibrate that solution. Chemical yield is determined by immediate $\mathrm{Ge}(\mathrm{Li})$ counting of the plated $\mathrm{Tc}$ sample. The Tc- $99 \mathrm{~m}$ tracer activity is allowed to decay and then the planchet is beta counted to determine 
Tc-99 activity. A blank is also run with each set to check tracer purity. A purity check of the Tc-99 is made by recounting. Samples with beta activity greater than $3 \mathrm{cpm}$ are counted to check the characteristic half thickness through Al absorbers. Higher activity samples allow the low transmission end of the curve to be checked.

Iodine-129 samples are fused with $\mathrm{KF}, \mathrm{KOH}$ and $\mathrm{K}_{2} \mathrm{CO}_{3}$ in a $\mathrm{Ni}$ crucible in the presence of standardized I carrier. Equilibration is done by addition of sodium hypochlorite to oxidize all I to IO reduction to $I^{\circ}$. Purification is accomplished by a series of extraction procedures. The $I$ is extracted into the organic phases, either carbon tetrachloride or toluene, by adding sodium nitrite to oxidize I to $I^{\circ}$. It is back-extracted in to the aqueous phase by adding bisulfite to reduce $I^{\circ}$ to $I$. Three cycles are performed. The iodine solution is precipitated as CuI and yielded gravimetrically. The I-129 is counted on either a thin $\mathrm{NaI}(\mathrm{Tl})$ gamma spectrometer, or a HPGe gamma spectrometer detector. The spectrum is plotted and resolved by computer analysis.

sequential chemical separation procedure is used to separate tracers and carriers and equilibrated sample activity in the analyses of $\mathrm{Sr}$ and $\mathrm{Pu}$. Separated components are further purified for yield and radioactivity measurement. In these analyses, $\mathrm{Sr}-85$ and $\mathrm{Pu}-242$ are used as tracers and $\mathrm{Sr}$ and $\mathrm{Y}$ are used as carriers. The $\mathrm{Sr}-85$ is added in case a backup reanalysis of Sr-90 is needed. Sr-85 eliminates the problem of elemental $\mathrm{Sr}$ in samples. Aliquots of standardized tracers (Sr-85 and Pu-242) and aliquots of $\mathrm{Sr}$ and $\mathrm{Y}$ carriers are added to the aliquot of the dissolved sample. The mixture is chemically treated to equilibrate carriers and tracers with the radioactive sample species.

Plutonium (IV) is separated on an anion exchange column from $8 \mathrm{~N} \mathrm{HNO}_{3}$ while $\mathrm{Sr}$ and $\mathrm{Y}$ pass through in the column load and washes. $\mathrm{Pu}$ is eluted with HF-HNO solution. The $\mathrm{Sr}$ is separated by repeated precipitations of $\mathrm{Sr}\left(\mathrm{NO}_{3}\right)_{2}$ from $\mathrm{HNO}_{3}$ solution.

A Sr-Y separation is done by extracting the $\mathrm{Y}$ into an HDEHP/Toluene mixture. It is backextracted into $\mathrm{HCl}$. Further decontamination is done by coprecipitating $\mathrm{Y}$ with $\mathrm{NH}_{4} \mathrm{OH}, \mathrm{HF}, \mathrm{NH}_{4} \mathrm{OH}$ again and finally oxalic acid. This last precipitate is ashed to the $\mathrm{Y}_{2} \mathrm{O}_{3}$ and mounted in a copper backed Mylar film sandwich on a 1-inch Nylon planchet. It is counted immediately and at intervals on one of 24 low background beta counters. Background for one group of counters ranges from 0.12 to $0.16 \mathrm{cpm}$, and 0.45 to $0.6 \mathrm{cpm}$ for another group. Each sample is counted for up to 5 times to check the decay of Y -90 .

A computer program calculates the $Y-90$ intercept at the time of milking by a least squares analysis, applies corrections for efficiency versus precipitate weight, counting efficiency, yield, aliquot, radioactive decay, etc. The computer prints a decay plot of the $\mathrm{Y}-90$ activity with time which can assist in data appraisal. The results are printed as $\mathrm{Sr}-90$, at time of collection, in $\mathrm{dpm} / \mathrm{g}$ or other chosen units with attendant errors.

The Pu elutriated by the HF-HNO 3 acid solution is boiled down. The anion exchange column extraction is repeated, adding hydrochloric acid wash and eluting the Pu with hydrochloric acid and ammonium iodide. The eluant is boiled to low volume and electroplated from an ammoni im sulfate electrolyte ( $\mathrm{pH} 2,1.2$ amperes, 30 minutes) onto a 1-inch stainless steel disc. 
The Pu-238 sample is counted by alpha spectrometry. The alpha spectrometry results are calculated by summing the counts recorded for the channels for the alpha peak or the energy region of interest. Each peak is corrected for detector background and tracer impurity. The final activity result for each isotope is determined by ratio calculation against the amount of tracer added.

Counting errors are estimated by the usual convention, i.e., a Poisson distribution is assumed. The error is estimated from the total gross counts of sample plus background and impurity corrections or each peak. The error in the tracer peak is propagated in the final answer. These combined errors typically range from 1.C percent for high level samples down to plus or minus several hundred percent of the estimated mean concentration.

\section{Soil Sampling and Analysis}

A sample of soil was analyzed for Tc-99, Sr-90, I-129, Cs-137, H-3, Pu-238, Pu-239,240, Ru106, and Sb-125 at the beginning of the experiment to determine the background levels of these radionuclides. The soil dissolution procedure consists of an ashing step in which the sample is charred and ashed by pyrolysis in an aluminum foil covered beaker. The residue is dissolved by repeated treatments with $\mathrm{HF}$ and $\mathrm{HNO}_{3}$, plus $\mathrm{HCl}$ and $\mathrm{H}_{3} \mathrm{BO}_{3}$. Any insoluble material is filtered off, ashed and treated again. A metathesis step, with $\mathrm{NaOH}$, is used for more difficult residues, followed by the above acid dissolution cycles. All of the filtrates of dissoived soil are combined for analysis. Analysis of individual nuclides proceeds as previously described for vegetation.

\section{Water Sampling and Analysis}

Two types of water samples were collected. A 4-liter sample was collected for radionuclide analysis. The analysis was done by TMA/Norcal of Richmond, California. Figure 3. shows the sampling schedule followed throughout the experiment. Initially, samples were collected every two months. As it became clear that the concentration of radionuclides was not changing rapidly, the frequency of sampling was changed to twice a year. This was later reduced to once a year because, as the vegetation matured, water use increased to the point that no water was drained from the lysimeters during the summer. In the tree plots, the combination of the high water use of the trees and successive dry years resulted in no water drainage to the sumps during 1987 or 1988.

Analytic procedures for the radionuclide analysis of the water samples are similar to those used for the vegetation except that the nuclides are already in solution and the steps used to dissolve the vegetative material do not apply.

Water samples were also analyzed for the nonradioactive ions and elements: nitrate nitrogen, nitrite nitrogen, Kjeldahl nitrogen, sulfates, total mercury, total aluminum, total boron, total chromium, $\mathrm{pH}$, and conductivity. Initially the sumps were sampled monthly. As illustrated in Figure 3., the frequency of sampling was decreased to bimonthly and finally quarterly for the same reasons cited for the radionuclide analyses. The analyses were done by Normandeau, Inc. of New Ellenton, S.C. 
Table 3. Nonradioactive Sump Water Analysis Procedures

\begin{tabular}{|c|c|c|c|}
\hline Analusis & Procedure & Reference* & $\begin{array}{l}\text { Detection } \\
\text { Limits }\end{array}$ \\
\hline Conductivity & $\begin{array}{l}\text { Specific Conductance } \\
\text { Electrode }\end{array}$ & EPA 120.1 & $1 \mu \mathrm{mho}$ \\
\hline Nitrate & $\begin{array}{l}\text { Automated Hydrazine } \\
\text { Reduction }\end{array}$ & EPA 353.1 & $0.01 \mathrm{mgN} / \mathrm{L}$ \\
\hline Nitrite & $\begin{array}{l}\text { Automated Hydrazine } \\
\text { Reduction }\end{array}$ & EPA 353.1 & $0.001 \mathrm{mgN} / \mathrm{L}$ \\
\hline $\begin{array}{l}\text { Total Kjeldahl } \\
\text { Nitrogen }\end{array}$ & $\begin{array}{l}\text { Automated Cadmium } \\
\text { Reduction }\end{array}$ & EPA 353.2 & $0.2 \mathrm{mgN} / \mathrm{L}$ \\
\hline Sulfate & Turbidimetric & EPA 375.4 & $1 \mathrm{mgSO}_{4} / \mathrm{L}$ \\
\hline Chromium & $\begin{array}{l}\text { Inductively Coupled } \\
\text { Plasma }\end{array}$ & EPA 200.7 & $0.02 \mathrm{mg} / \mathrm{L}$ \\
\hline Boron & $\begin{array}{l}\text { Inductively Coupled } \\
\text { Plasma }\end{array}$ & EPA 200.7 & $0.04 \mathrm{mg} / \mathrm{L}$ \\
\hline Aluminum & $\begin{array}{l}\text { Inductively Coupled } \\
\text { Plasma }\end{array}$ & EPA 200.7 & $0.05 \mathrm{mg} / \mathrm{L}$ \\
\hline Mercury & Manual Cold Vapor & EPA 245.1 & $0.0001 \mathrm{mg} / \mathrm{L}$ \\
\hline
\end{tabular}


The list of radionuclides and nonradioactive elements and ions $t$ t be determined was chosen on the basis of their abundance in the saltstone and their long half-life, or potential for health effects. Tc99 was chosen because it cormprises $40 \%$ of the activity in the saltstone (see Table 2 in previous section). Nitrate is the nost abundant nonradioactive water-quality constituent in saltstone, Cs-137 and I-129) have a significant potential for uptake into the foodchain. Pu-238, Pu-239,240, chromium, and mercury are present in very small amounts, but have significant health effects potential.

\section{RESULTS}

Data analysis was done in three steps. First the data was tabulated in summary form with averages taken for the type of vegetation, type of treatment, and date on which samples were taken. This provided a rough approach to determining if there were any relationships between the concentration of radionuclides or chemical elements and the type of vegetation, type of treatment, or time after start of the experiment. This analysis was followed by a statistical analysis of the data to determine if the difference in means found in the tables were likely to be from the differences in vegetation type, treatment type, and date, or were from random chance. These two methods were used to identify radionuclides or chemical elements that seemed to warrant further analysis. The concentrations of radionuclide and chemical species were graphically displayed and the pattern of concentration in time and among treatments and vegetation types were investigated. The conclusions drawn about the importance of radionuclide or element uptake from saltstone by vegetation were made on the basis of all the steps taken in the analysis.

\section{Statistical Analysis of Data}

The design of this experiment was made on the basis of the information desired: 1) will vegetation take up materials from buried saltstone, 2 ) is there a difference in uptake among the types of vegetation, and 3 ) is there a difference in uptake for different burial depths and conditions of saltstone. The expense of the lysimeters limited the number of experimental units. For this reason, the design has some limitations which make statistical analysis difficult.

Only two replicates were used of each treatment for each vegetation type. Since crops were likely to have shallow roots, they were grown only on lysimeters having saltstone buried at the shallower depths. Trees were expected to have deep roots and were grown only on lysimeter having saltstone buried at the greater depth. Only in the case of grass was a complete set of depths used for a single vegetation type. In addition, one of the two control lysimeters which contained trees was sacrificed for another of experiment. Problems were also caused by missing data from the death of sample vegetation and from lack of water in the lysimeter sumps during periods of drought.

The statistical analysis was done by using the Analysis of Variance technique as developed in the SAS General Linear Models procedure. The sums of squares due to difference in the replicates was used as the error sums of squares in determining the significance of treatments. The analysis was done separately for the vegetation and sump water of each vegetation type. The measurements made before 1986 were not included in the analysis because examination of the data indicated that none of the radionuclides or chemical elements had left the saltstone and entered the sump water or vegetation before 
this time. This was done to make it easier to detect differences between the control and treated lysimeters, if any differences existed.

The F-static probabilities of the null hypothesi: that there was no difference between treatments, were used to look for differences. The lower the probability, on a scale of 0 to 1.0 , then the more likely that there is an effect of treatment. If this probability were less than 0.05 it is usually assumed that it is reasonable to conclude that there are treatment effects. In this case, the probability of difference between pairs of treatments was determined by the Bonferroni technique to try to determine which factors influencing the treatments were important. If the probability of a treatment effect was found to be less than 0.05 , the Bonferroni technique was still used to see if there were any treatment means that were significantly different from other treatment means. This latter comparison was done specifically to determine if the con'rol lysimeters were different than the lysimeters with burled saltstone even when there was no effect due to depth of burial.

\section{Vegetation Uptake of Radionuclides and Chemical Elements}

In Tables A.1, A.2, A.3 and A.4 of the Appendix, the concentrations of radionuclides and chemical elements have been averaged by date of collection, by treatment, and by both treatment and date of collection. Inspection of the data does not indicate many consistent differences due to the date of collection or the treatments. The most obvious pattern is the much lower concentration of $\mathrm{Tc}-99 \mathrm{in}$ the vegetation growing in the control lysimeters. This is true for all vegetation types and all sampling times after 1984. There does appear to an increase in concentration between 1985 and 1986 followed by some decrease in 1988 and 1989 in the grass lysimeters. This pattern is not as clear in the tree and crop lysimeters where fewer samples were taken during this period.

The only other concentrations that are noticeably different from the mean are the Pu-239 concentration measured in 1985. These concentrations are much higher than those measured during any other period. A closer examination of the data shows that these averages are based on a relatively few higher concentrations with all other concentrations below the level of detection. The 1984 and 1985, measurements were made by a different laboratory and it appears their level of detection was lower than the measurements made later. If these measurements vere averaged with the lowest level of detection for all the other samples, the concentration would be similar to those measured later, although the variability would still be greater. These measurements were not used in later analysis of the data.

The results of statistical analysis of the data are presented in Table 4. The results show the expected significant effect of treatment in the Tc-99 data for the grass and crop lysimeters. The comparison of the controls to all of the lysimeters containing saltstone indicates a significant effect of the saltstone. In addition to the Tc-99 concentration, a significant difference in the saltstone and control lysimeters is found for Cs-137 in the grass and tree lysimeters, and for $\mathrm{H}-3$ and organic nitrogen (total Kjeldahl nitrogen) in the seed of crops grown in the crop lysimeter. Therefore a further analysis was made of the Tc-99, and Cs-137. The differences between $\mathrm{H}-3$ and organic nitrogen in the control and other treatment lysimeters were too small to be of practical significance. The seed was air dried and had not received water from the roots for some time before harvest. The nitrogen effect in the crop could 
Table 4. Analysis of Variance Probabilities of an Effect of Treatment on Vegetation Concentrations

$\begin{array}{lllll}\begin{array}{l}\text { Radionuclide } \\ \text { or Element }\end{array} & \text { Grass } & \text { Trees } & \text { Vrop-Veg } & \text { Crop-Seed } \\ & & & & \\ \text { Tc-99 } & 0.0503^{*} & 0.6777 & 0.0351^{*} & 0.0105^{*} \\ \text { Cs-137 } & 0.2255^{*} & 0.1746^{*} & 0.5626 & 0.0741 \\ \mathrm{Hg} & \text { ND } & \text { ND } & \text { ND } & \text { ND } \\ \text { H-3 } & 0.0424 & 0.9904 & \text { ID } & 0.6952^{*} \\ \text { I-129 } & \text { ND } & \text { ND } & \text { ND } & \text { ND } \\ \text { Pu-238 } & 0.1584 & 0.0150 & 0.4729 & 0.4770 \\ \text { Pu-239/240 } & 0.3178 & 0.8393 & 0.5239 & 0.6547 \\ \text { Ru-106 } & \text { ND } & \text { ND } & \text { ND } & \text { ND } \\ \text { Sb-125 } & \text { ND } & \text { ND } & \text { ND } & \text { ND } \\ \text { Sr-90 } & 0.6392 & 0.8159 & 0.1020 & 0.7873 \\ \text { S } & 0.7604 & 0.1747 & 0.5931 & 0.1651 \\ \text { TKN } & 0.4040 & 0.3349 & 0.2294 & 0.0314^{*}\end{array}$

* All treatments significantly greater than controls at the $95 \%$ confirerce level using the paired Bonferroni test.

ND Below detection level of analysis used for all samples.

ID Insufficient data to make calculations. 
real since the crop could get additional nitrogen from the saltstone but it is hard to explain the effect being present in the seeds and not the crop or other type of vegetation.

\section{Technetium-99}

The results of the Tc-99 measurements are illustrated in Figures 4, 5, 6, and 7. The most outstanding feature of these figures is the very low concentration and very low variability of the control lysimeters. There is less variation in the control lysimeter between vegetation types than between the measurements of any other treatment in the same vegetation type. This is not surprising if the source of the Tc-99 is the saltstone in the lysimeters.

There appears to be a general time trend in the concentrations in the grass lysimeters. The Tc-99 concentrations are low early in the experimental period and rise to a peak around 1986. The concentrations then decrease in 1987 and hold at about the same level in 1988 (measurements made in the winter of 1988-89). The time trend in the tree needle and crop concentration is not as clear. Samples of tree needles were not taken before 1986 and the early period of low uptake was not recorded in the tree lysimeters. Crops were not grown in the crop lysimeters in 1986 or after 1987 . The five crops grown (one in 1984 for which there was no concentration above the detection limit and two in 1985) support the trend found in the grass lysimeters of little or no uptake before 1986 , followed by higher uptake in 1987.

There is little difference in the peak concentration between types of vegetation. The corn grown in 1987 in the crop lysimeter had the highest concentration of all the vegetation. This crop was grown at the time that the peak concentration of Tc- 99 would be expected in the lysimeter soil, based on the concentration found in the lysimeters sumps. The low uptake before 1986 appears to be related to the availability of Tc-99 from the saltstone. It will be shown in a later section that this is supported by the concentration of $\mathrm{Tc}-99$ in the lysimeter sump water. All lysimeters containing saltstone show an increase in the Tc-99 in the vegetation after 1986 above that found before that time or at any time in the controls.

The other notable finding is the comparatively low levels of Tc-99 in the crop seeds when compared to vegetation (leaves) from the same crops. The kernel concentrations in corn plants is three orders of magnitude less than those in the leaves. The difference in concentration between the seed and vegetative parts of the soybean is not as great but still a factor of 10 less. In both crops grown in 1987, the seeds grown in the control lysimeters are still less than those grown in any of the other lysimeters. The lower concentration in crop seed has been documented elsewhere and appears to be caused by differences in the chemical constituents between vegetative and reproductive organs of plants ${ }^{6}$

\section{Cesium-137}

As shown in Figure 8, the concentration of Cs-137 in the grass is much lower than the concentration of Tc-99 and the difference between the vegetation grown in control lysimeters and vegetation grown in lysimeters containing saltstone is much less. However, with one exception during 1985, the Cs- 137 concentration in the grass grown on the control lysimeters was always less than the 


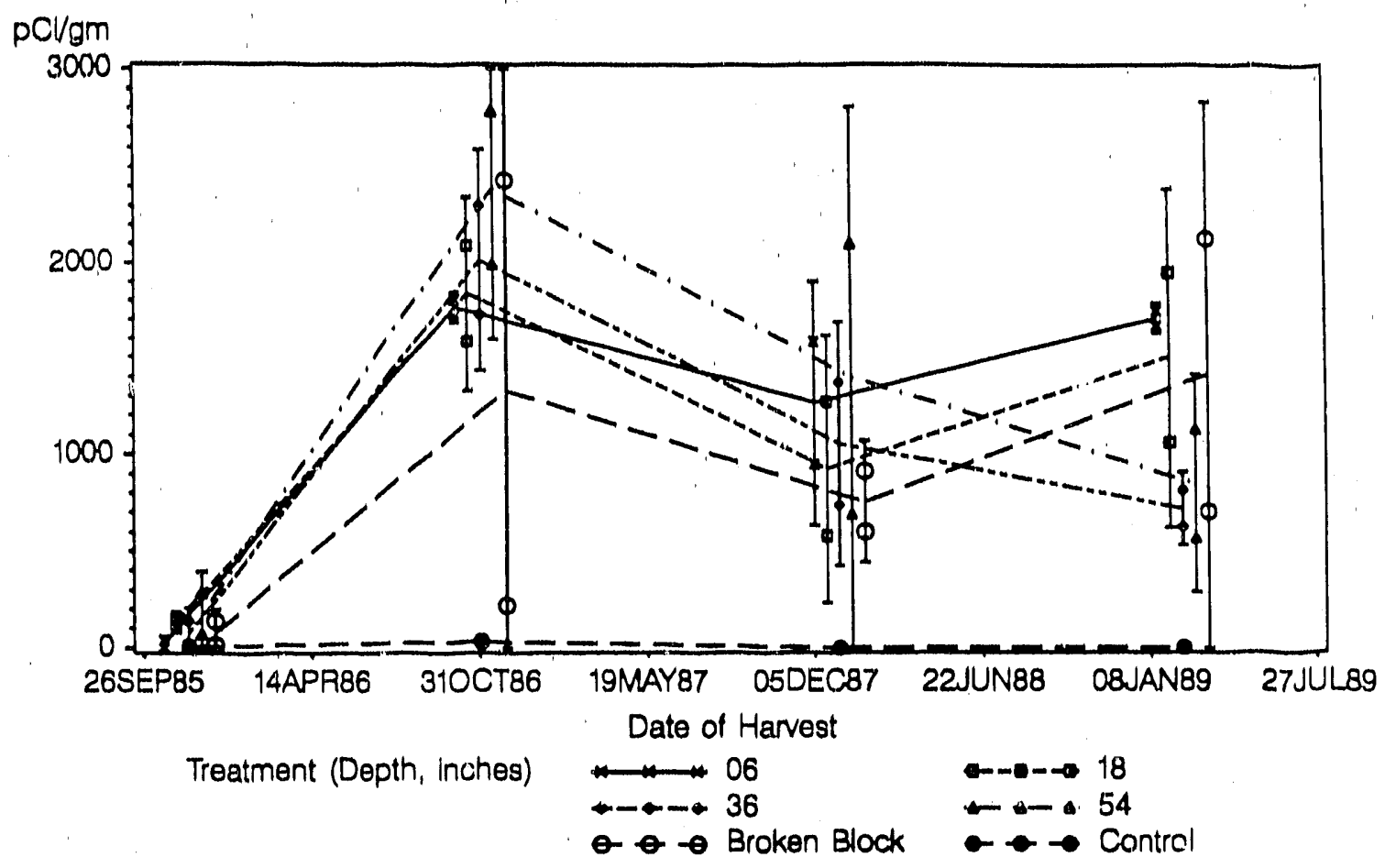

Figure 4. Technetium Concentrations, Concentration Means, and Two Standard Deviation Error Bars for Grass.

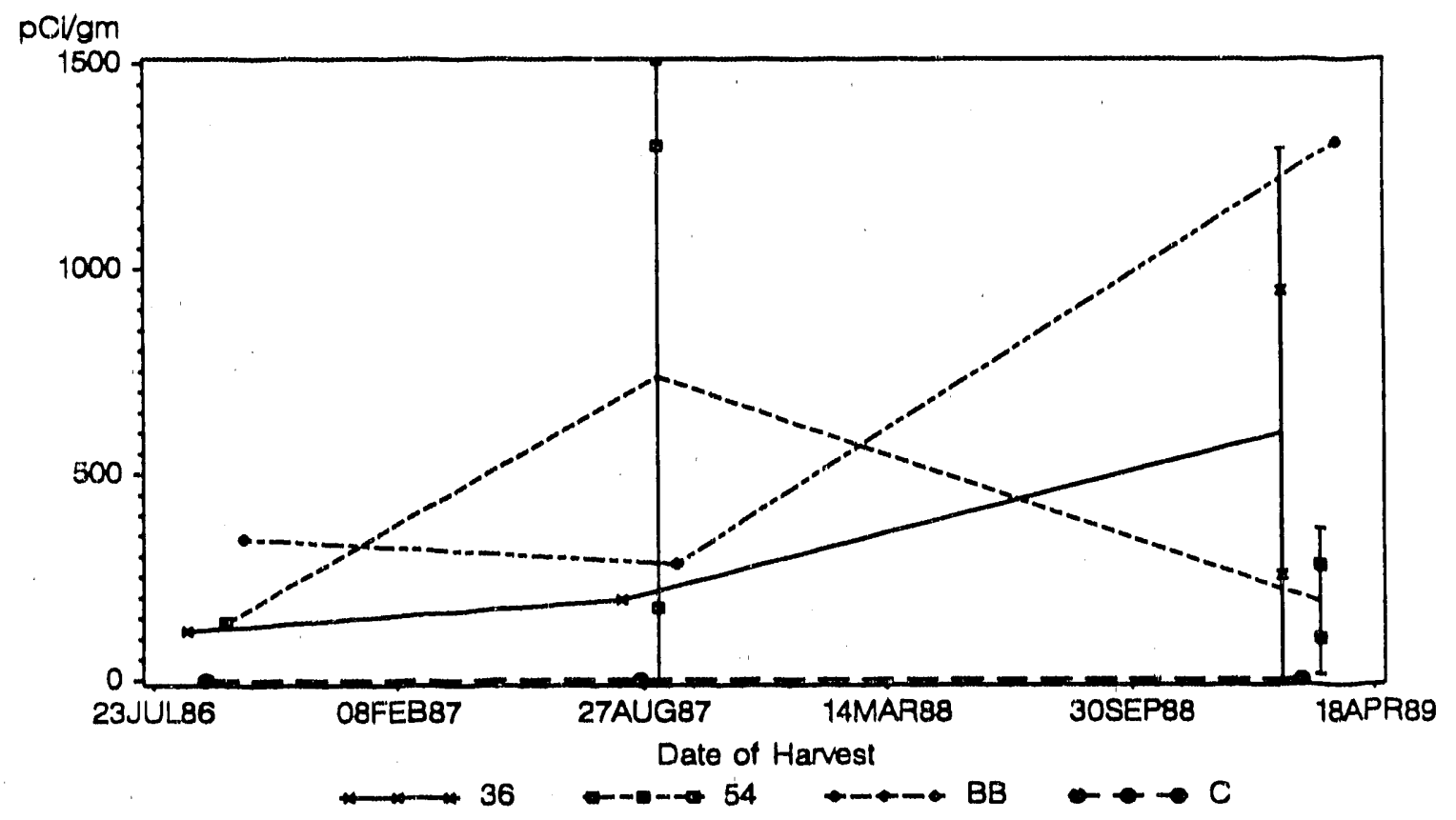

Figure 5. Technetium Concentration, Concentration Means, and Two Standard Deviation Error Bars for Trees. 


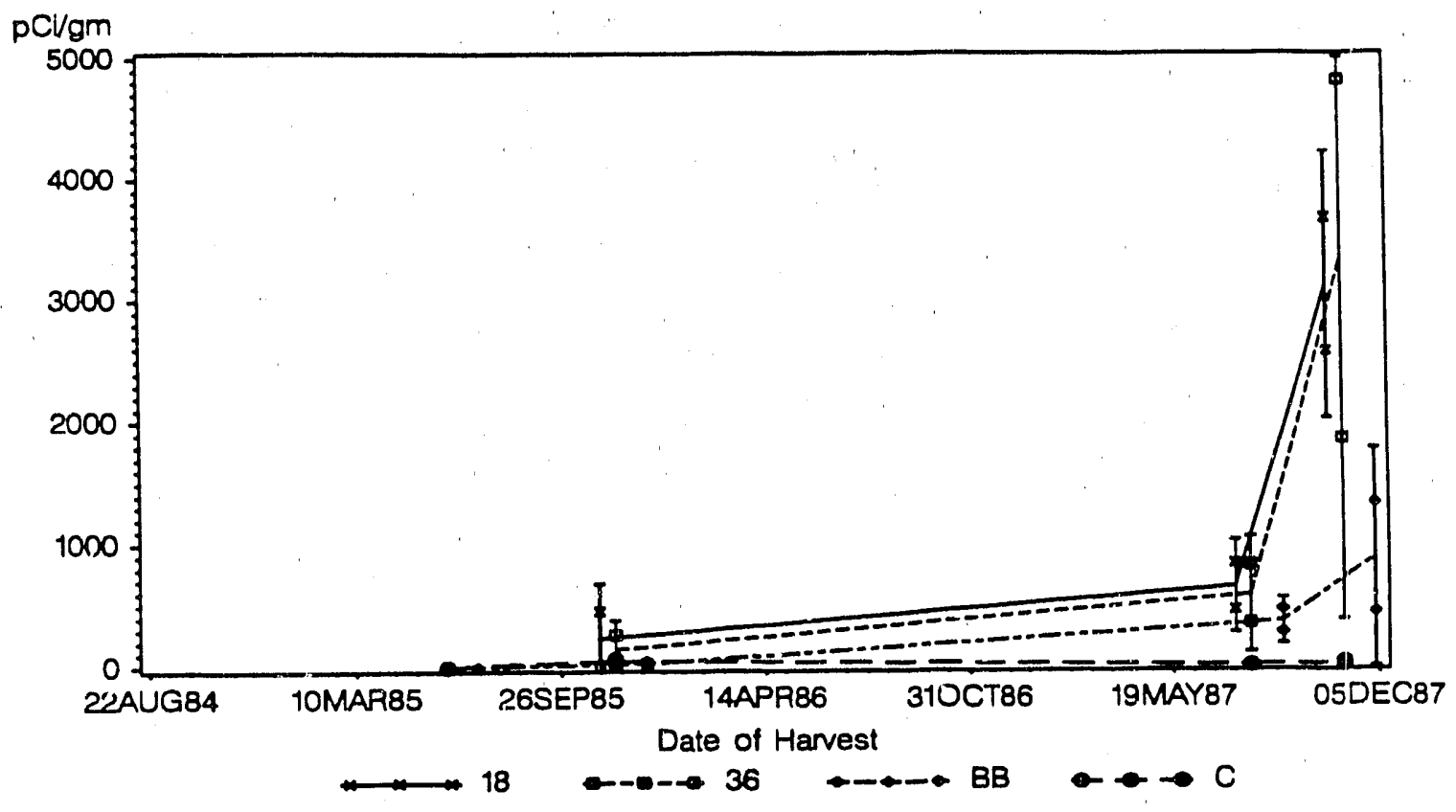

Figure 6. Technetium Concentrations, Concentration Means, and Two Standard Deviation Error Bars for Crop Vegetative Parts.

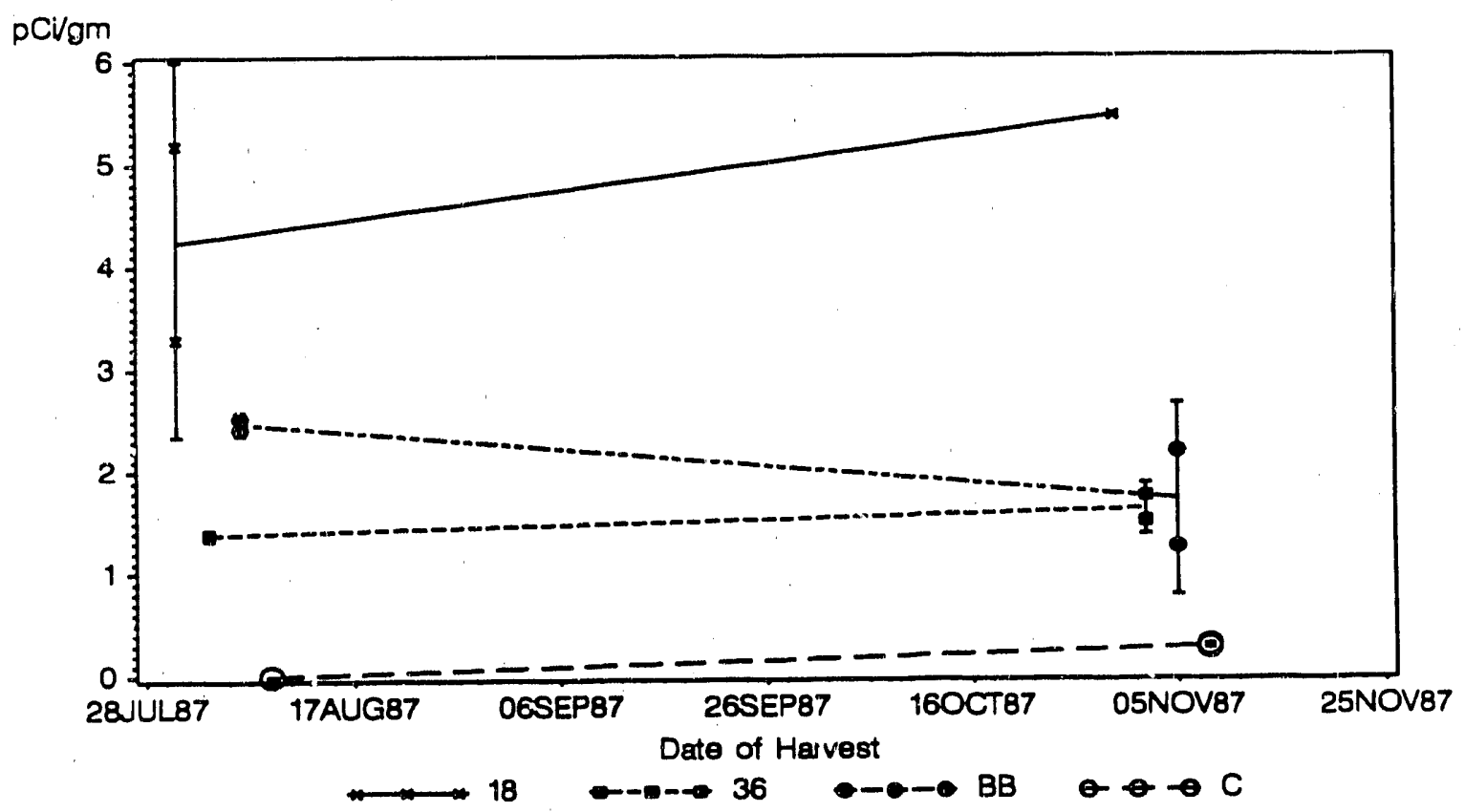

Figure 7. Technetium Concentrations, Concentration Means, and Two Standard Deviation Error Bars for Crop Seeds. 


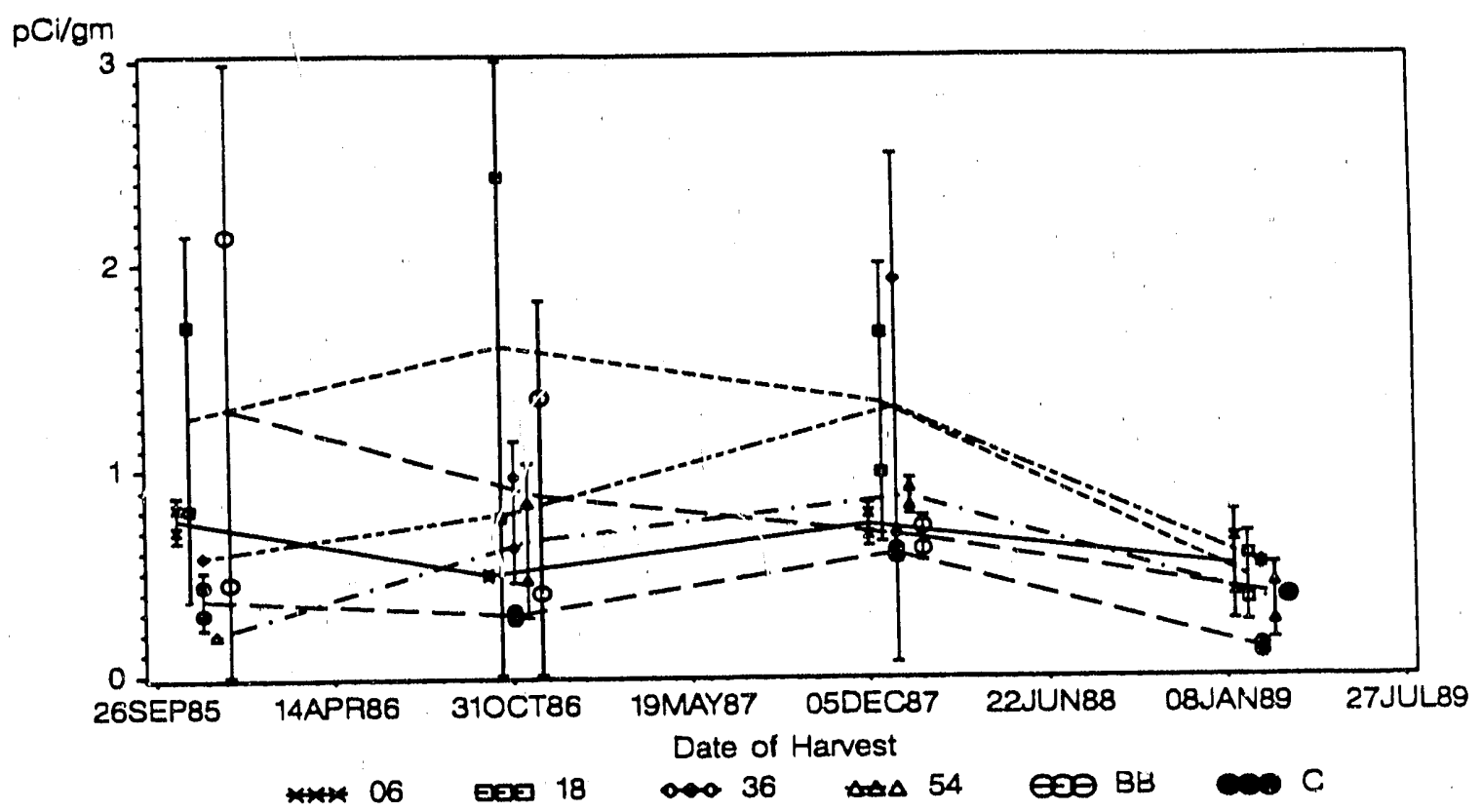
Figure 8. Cesiuim-137 Concentration, Concentration Means, and Two Standard Deviation
Error Bars for Grass

grass grown on any of the lysimeters containing saltstone.

The lag in uptake, and the corresponding peak in 1987 found in the Tc-99 lysimeters is not as clearly defined in the Cs-137 concentrations. There does appear to be a trend toward lower concentrations in the 1989 samples. The results for the other vegetation types appear to be similar, though the smaller number of samples make it more difficult to follow any trends.

\section{Radionuclide and Chemical Concentrations in Lysimeter Sump Water}

The surface of soil solicis tends to be negatively charged and repel negatively charged ions in soil solution. For this reason, anions generally move freely with soil water and the concentration of anions that the water collected from the sumps at the bottom of the lysimeters is a measure of the concentration of these constituents in the soil water. The same is not true for cations. Depending on the type of soil, there is considerable capacity for cation absorption in soils. It is possible for the concentration of cations in soil solution to change as cations are absorbed in a soil column. The various cations in solution will compete for the available cation exchange capacity. The addition of one type of cation may lead to the release of another cation as that cation is displaced at the exchange surfaces.

Cation exchange can eliminate certain materials from the sump water that are found in the 
vegetation. This appears to be the case for Cs-137. Cs-137 is found in the vegetation from all the lysimeters and appears to be taken up by the plants (some Cs-137 reached the plants by fallout from the atmosphere). However, there is no measurable Cs-137 in the sump water.

Because anion mobility in soil is high and cation mobility is restricted by absorption, the discussion of radionuclides and chemical materials in the sump water is almost totally limited to a discussion of the materials that are anions in solutions of soil water. As shown in Tables A.5, A.6, and A.7 of the Appendix for the chemical materials, the materials that show differences with treatment are the anions nitrate, nitrite, and sulfate. The main treatment differences appear to be in the control versus all other treatments. The same pattern of anionic mobility is found for the radionuclides (Tables A.8. A.9, and A.10 of the Appendix) where Tc-99 is the only radionuclide that appears to have a greater concentration in the lysimeters containing saltstone than in the control lysimeters.

The statistical analysis (Table 5) confirms the choice of radionuclides and chemical constituents that are mobile in the sump water, with the exception of nitrite where the differences are not statistically significant. The statistical analysis also indicates that in some cases there is an increase in concentration in the water from the lysimeters which contained broken blocks. This contrasts with the fact that in no case was there an increase in the concentration of radionuclides in vegetation grown on the broken block lysimeters as compared to the other lysimeters containing saltstone.

\section{Nitrate}

As shown in Table 2, nitrate is the primary anion found in saltstone. Generally there is a low capacity for absorption of nitrate in soils and it can be expected that the nitrate concentration of the sump water reflects the nitrate concentration of the soil water (appropriately lagged for the time it takes for the water to percolate through the soil column). The nitrate concentrations in the sump water, as shown in Figures 9, 10, and 11) are characterized by a period of little or no increase in concentration above controls before late in 1985 . The initial lag is followed by a rapid increase in all the lysimeters containing saltstone blocks, with a peak concentration in 1986 or 1987 . Following the peak, it is difficult to tell if the concentrations in 1988 and 1989 are still decreasing or have reached a constant level. For all three vegetation types, the concentrations in the control lysimeters remain low and the highest concentrations during the peak period are found in the sump water of the broken block lysimeters.

The concentration of nitrate in the sump water of the grass and crop lysimeters is very similar. The peak concentrations in the tree lysimeters is somewhat lower. However, the high evaporation of water from the tree lysimeters severely limited the volume of water percolating through the lysimeter soil (and the water available to sample) after 1986 and it is possible that the nitrate may still be retained in the soil of these lysimeters. 
Table 5. Analysis of Variance Probabilities for an Effect of Treatment for Sump Water Concentrations

\begin{tabular}{llll}
$\begin{array}{lll}\text { Radionuclide } \\
\text { or Element }\end{array}$ & Grass & Trees & Crop-Veg \\
\cline { 2 - 3 } $\mathrm{Al}$ & 0.0054 & 0.0316 & 0.3957 \\
$\mathrm{~B}$ & 0.0174 & $\mathrm{ID}$ & $\mathrm{ID}$ \\
Conductivity & $0.0126^{*+}$ & $0.0479^{*+}$ & $0.1255^{*+}$ \\
$\mathrm{Cs}-137$ & $\mathrm{ND}$ & $\mathrm{ND}$ & $\mathrm{ND}$ \\
$\mathrm{Cr}$ & 0.0033 & 0.2923 & 0.6521 \\
$\mathrm{Hg}$ & 0.0559 & 0.2782 & 0.3077 \\
$\mathrm{H}-3$ & 0.0597 & 0.0159 & 0.3422 \\
$\mathrm{I}-129$ & $\mathrm{ND}$ & $\mathrm{ND}$ & $\mathrm{ND}$ \\
$\mathrm{NO}$ & 0.5241 & 0.2766 & 0.4721 \\
$\mathrm{NO}_{3}$ & $0.0398^{*+}$ & $0.0088^{*+}$ & $0.11507^{*+}$ \\
$\mathrm{pH}$ & $0.0704^{*+}$ & 0.3821 & 0.0340 \\
$\mathrm{Pu}-238$ & $\mathrm{ND}$ & $\mathrm{ND}$ & $\mathrm{ND}$ \\
$\mathrm{Pu}-239 / 240$ & $\mathrm{ND}$ & $\mathrm{ND}$ & $\mathrm{ND}$ \\
$\mathrm{Sb}-125$ & $\mathrm{ND}$ & $\mathrm{ND}$ & $\mathrm{ND}$ \\
$\mathrm{SO}$ & $0.0055^{*}$ & $0.0224^{*+}$ & $0.0891^{+}$ \\
$\mathrm{Sr}-90$ & $0.0510^{+}$ & 0.4152 & 0.2800 \\
$\mathrm{Tc}-99$ & $0.0280^{1}$ & $0.5283^{!}$ & $0.0766^{\prime}$ \\
$\mathrm{tkn}$ & 0.0043 & 0.4256 & 0.4366
\end{tabular}

* Water from control lysimeters significantly different and of lower concentration than water from all other treatments using Bonferroni paired comparisons.

+ Water from broken block lysimeters significantly different and of greater concentration than water from all other treatments using Bonferroni paired comparisons.

! Water from control lysimeters of lower concentration than than water from all other treatments and water from broken block of higher concentrartion than water from all other treatments with these two treatments significantly different from each other but not significantly different from all other treatments.

ND Below detection level of analysis used for all samples.

ID Insufficient data to make calculations. 


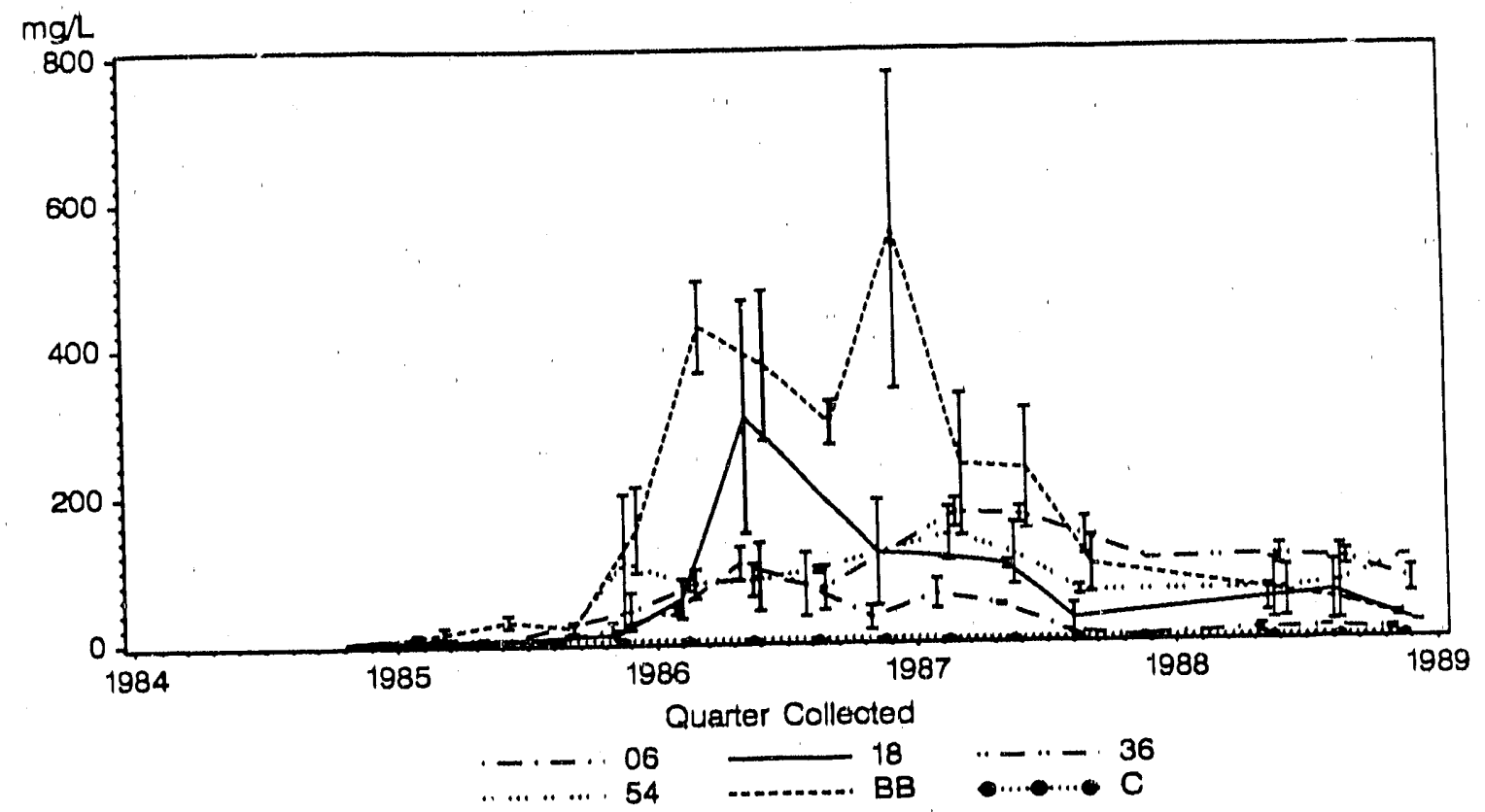

Figure 9. Mean Nitrate Concentration and One Standard Deviation of the Mean in Sump Water of Grass Lysimeters.

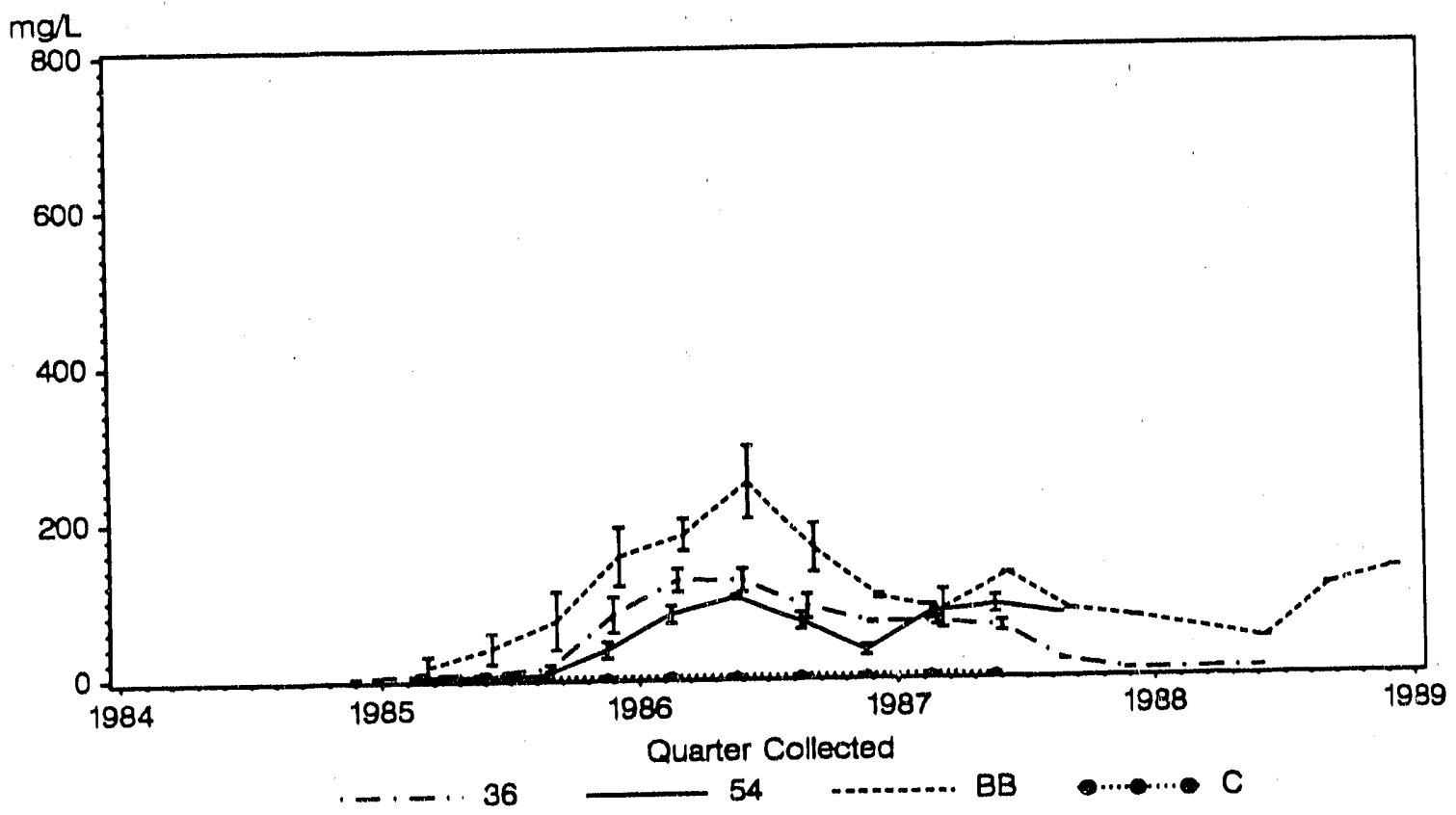

Figure 10. Mean Nitrate Concentration and One Standard Deviation of the Mean in Sump Water of Tree Lysimeters 


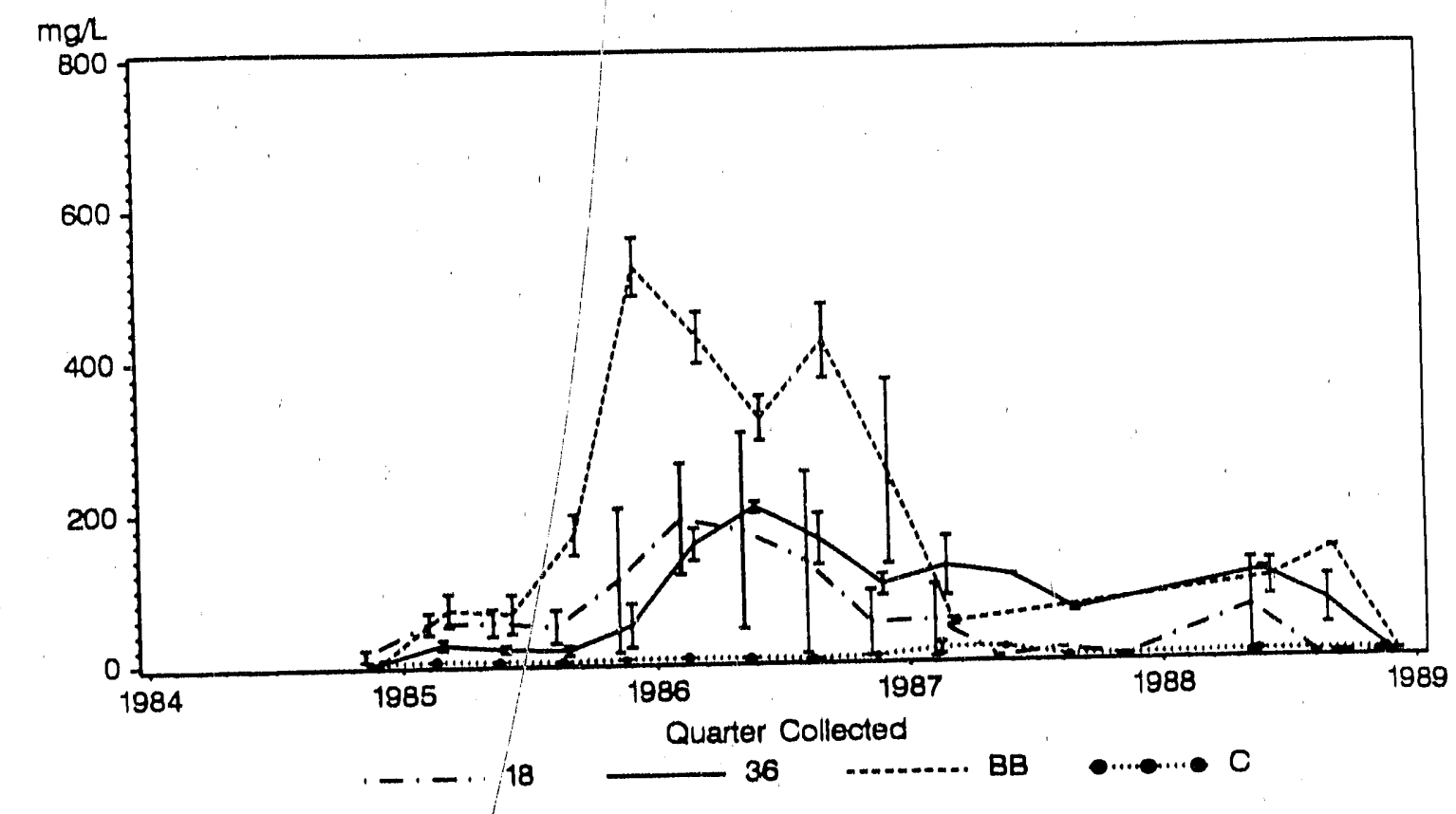

Figure 11. Mean Nitrate Concentration and One Standard Deviation of the Mean in Sump Water of Crop Lysimeters.

\section{Sulfate}

Berause the concentration patterns for sulfate in the sump water is very similar for all vegetation types, only the grass lysimeter results are shown in Figure 12. The results are similar to the nitrate results in that the controls are lower than the lysimeters with saltstone blocks and the broken block lysimeters are higher than any of the other saltstone containing lysimeters once the peak in concentration has been reached. However, the lag before the peak was reached was much longer. It appears that the increase in concentration does not begin until 1987 and may have been reached in late 1988 or early 1989. No data are available to determine if the sulfate concentrations will decrease after the peak has been reached as was the case for nitrate.

\section{Conductivity}

As indicated in Tables A.5, A.6, and A.7 of the Appendix and Table 5, the conductivity of the soil water solution collected in the sump water is lowest in the control lysimeters and highest in the broken block lysimeters. Conductivity is a measure of the total ionic strength of the solution. Since the lysimeter sump water in the lysimeters containing saltstone is dominated by the anion nitrate, it is 


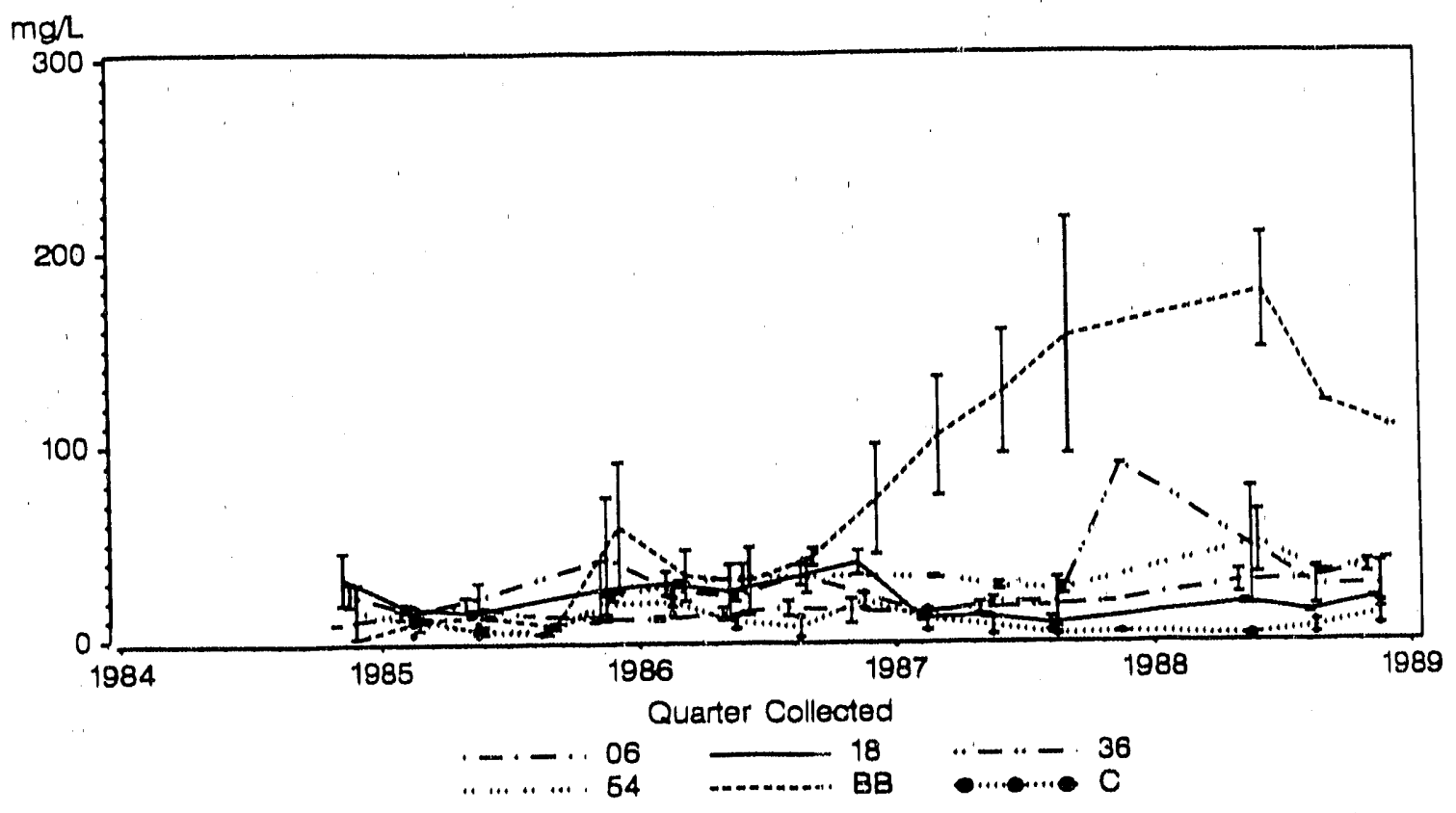
Figure 12. Mean Concentration of Sulfate and One Standard Deviation of the Mean in Sump
Water of Lysimeters Containing Grass.

reasonable to assume that the increase in conductivity is caused by the increase in the soluble nitrate salts. Figure 13 shows that conductivity and nitrate concentrations are very closely correlated, supporting the conclusion that they are related.

\section{Metals}

Even though the levels of heavy metals in the saltstone are low, their toxicity makes it necessary to determine their concentration in the soil water. As Tables A..5, A.6 and A.7 of the Appendix indicate, most of the time the levels of heavy metal in the soil water were below the detection limit. This supports the finding of no $\mathrm{Hg}$ in the vegetation. While the statistical summary does suggest some effect of treatment on the levels of heavy metals in the sump water, an inspection of the data show that the few samples which had concentrations above background did not show these levels to be higher or more frequent in the lysimeters containing saltstone than in the lysimeters containing no blocks (controls). In fact, in many cases the control lysimeters had the highest concentrations. This suggests that the saltstone is able to isolate these metals at the concentrations found in the supernate. 


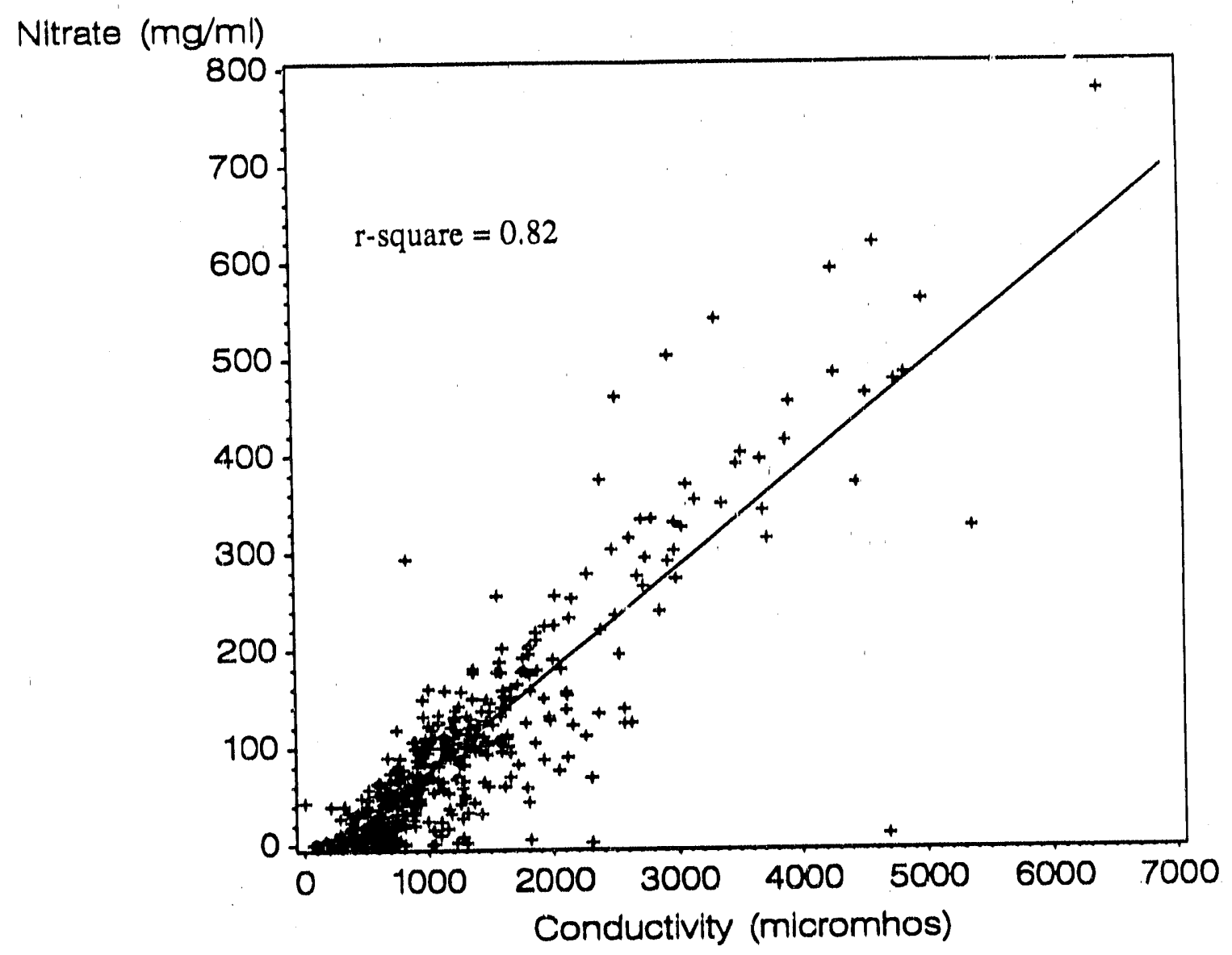

Figure 13. Correlation between Conductivity and Nitrate Concentration of Sump Water for All Lysimeters. 


\section{Technetium-99}

The results of measurements of Tc-99 in the lysimeter sump water for the three different types of vegetation are shown in Figures 14,15, and 16. The results are similar to those found for nitrate. There is a period of little or no increase in concentration before 1986, followed by a peak in 1987, and a decrease to a constant level in late 1987 and 1988. After the initial period, the sump water concentrations in the control lysimeters are always lower than those in the lysimeters containing saltstone. The sump water concentrations in the broken block lysimeters, with some exceptions, are higher than those in any of the other lysimeters containing saltstone.

Tc-99 is the only material measured in this study that is taken up by the vegetation and shows up in the lysimeter sump water. The trends in these two types of measurements are compared in Figures 17,18 , and 19 . When interpreting these trends it is necessary to understand the relationship between the measurements. There is a lag between the release of Tc-99 into the soil from the saltstone and when the water reaches the sump. Sump water accumulates during the winter and the spring. It is sampled during the winter and at the beginning of the summer, during years when two samples were collected. In years when only one sample is collected, the collection is generally made at the beginning of the summer. Therefore, in addition to the lag due to the transport time in the soil, there is also a lag due to the sampling

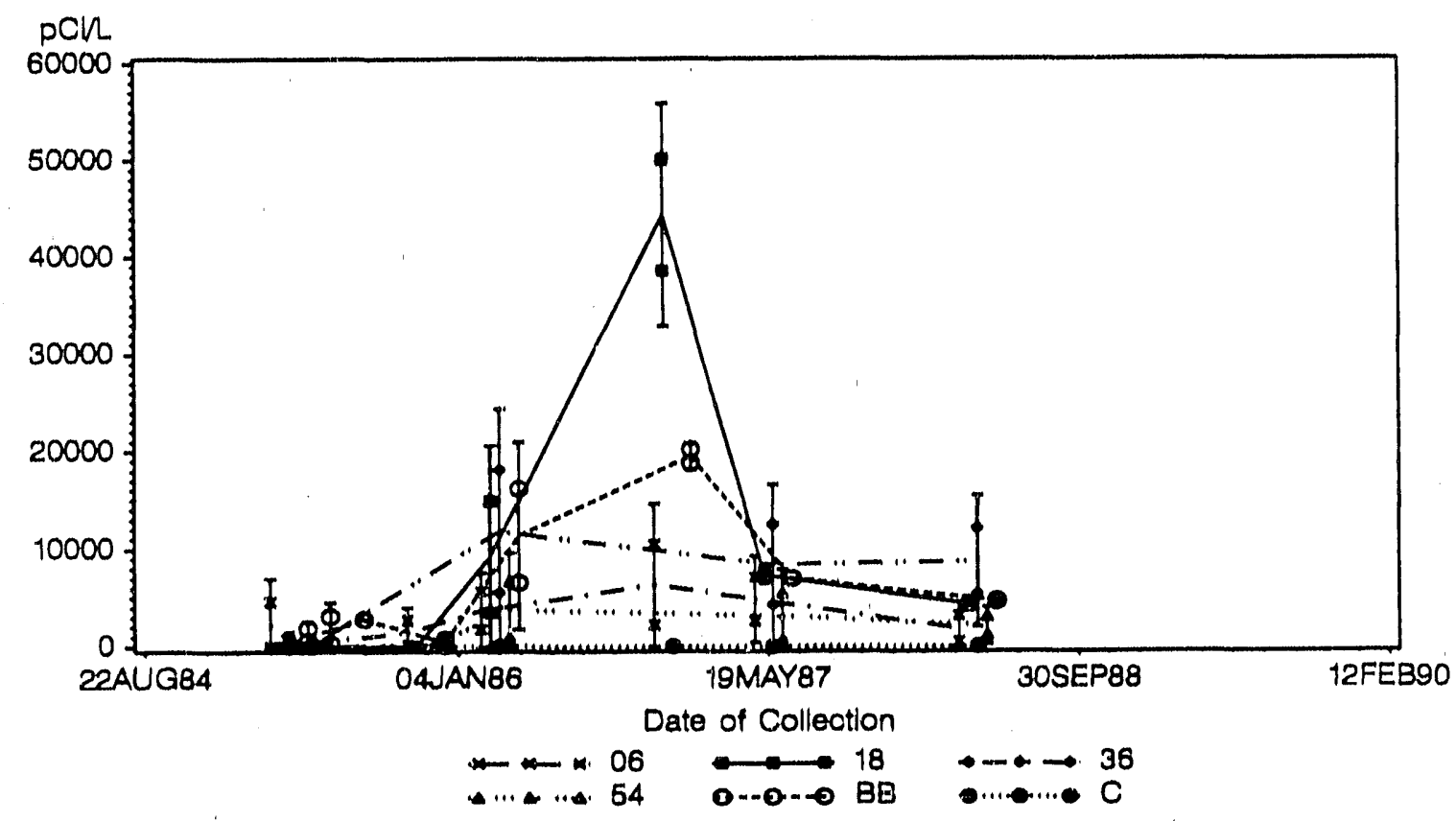

Figure 14. The Concentration, Mean Concentration, and One Standard Deviation of the Mean of Tc-99 in the Sump Water of the Grass Lysimeters. 


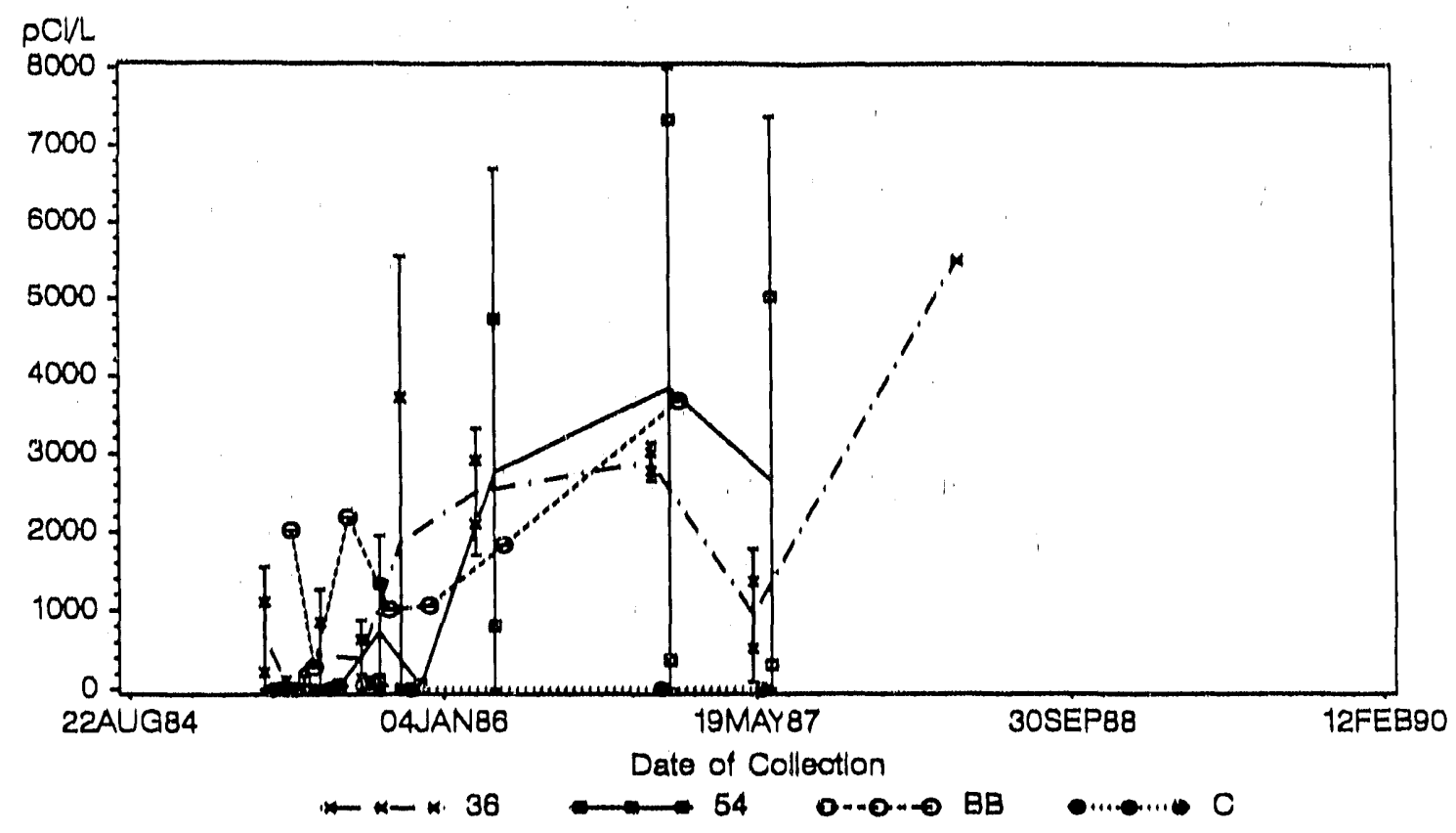

Figure 15. The Concentration, Mean Concentration, and One Standard Deviation of the Mean of Tc-99 in the Sump Water of the Tree Lysimeters.

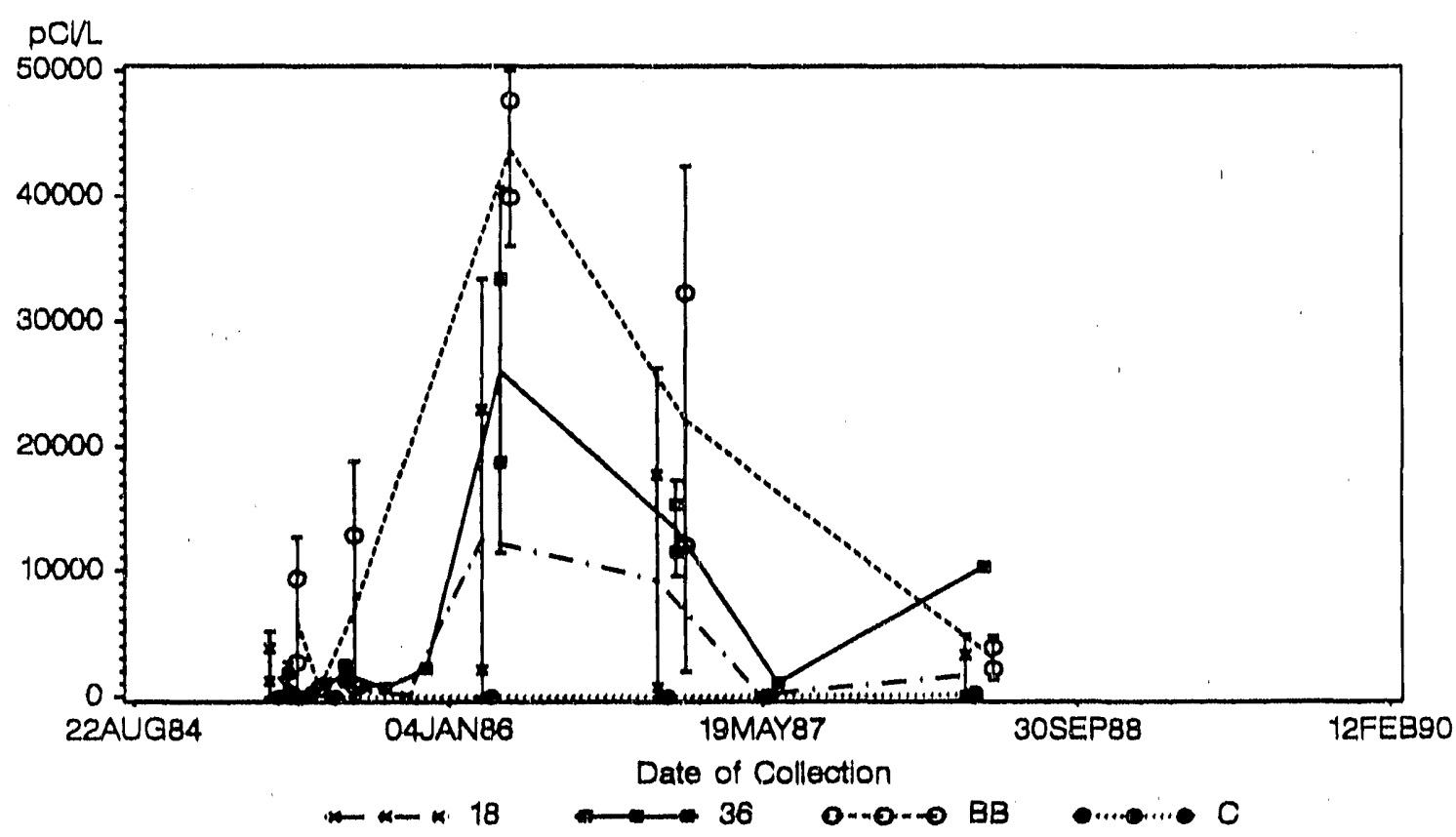

Figure 16. The Concentration, Mean Concentration, and One Standard Deviation of the Mean of Tc-99 in the Sump Water of the Crop Liysimeters. 
frequency,

Similarly, vegetation samples are collected at the end of the period of growth of a crop or after the period of growth of the grass or trees. The concentration of Tc-99 in the plant tissue is likely to be most affected by the concentration in the soll water during the perlod of growth. In most cases this will mean that the proper comparison between concentrations in the vegetation and the sump water wiil need to take the lags in sampling times and growth periods into account.

The comparison of Tc-99 in the grass and the lysimeter sump water shows a correspondence in the patterns of the two concentrations. This suggests that the grass takes up Tc-99 from the soll water after release from the saltstone. This, in turn, suggests that the lag in release of Tc-99 is relited to release from the saltstone. The concentrations in the needles show a definite lag behird the concentrations in the sump water. This can be explained by the fact that the species of pine used in these experiments, loblolly pine, retains its needles for two years. Each year the older needles were collected. This was done because the present years needles are usually the most efficient in providing food for the tree and it was decided that collecting these needles would least affect the vigor and chance of survival of the tree,

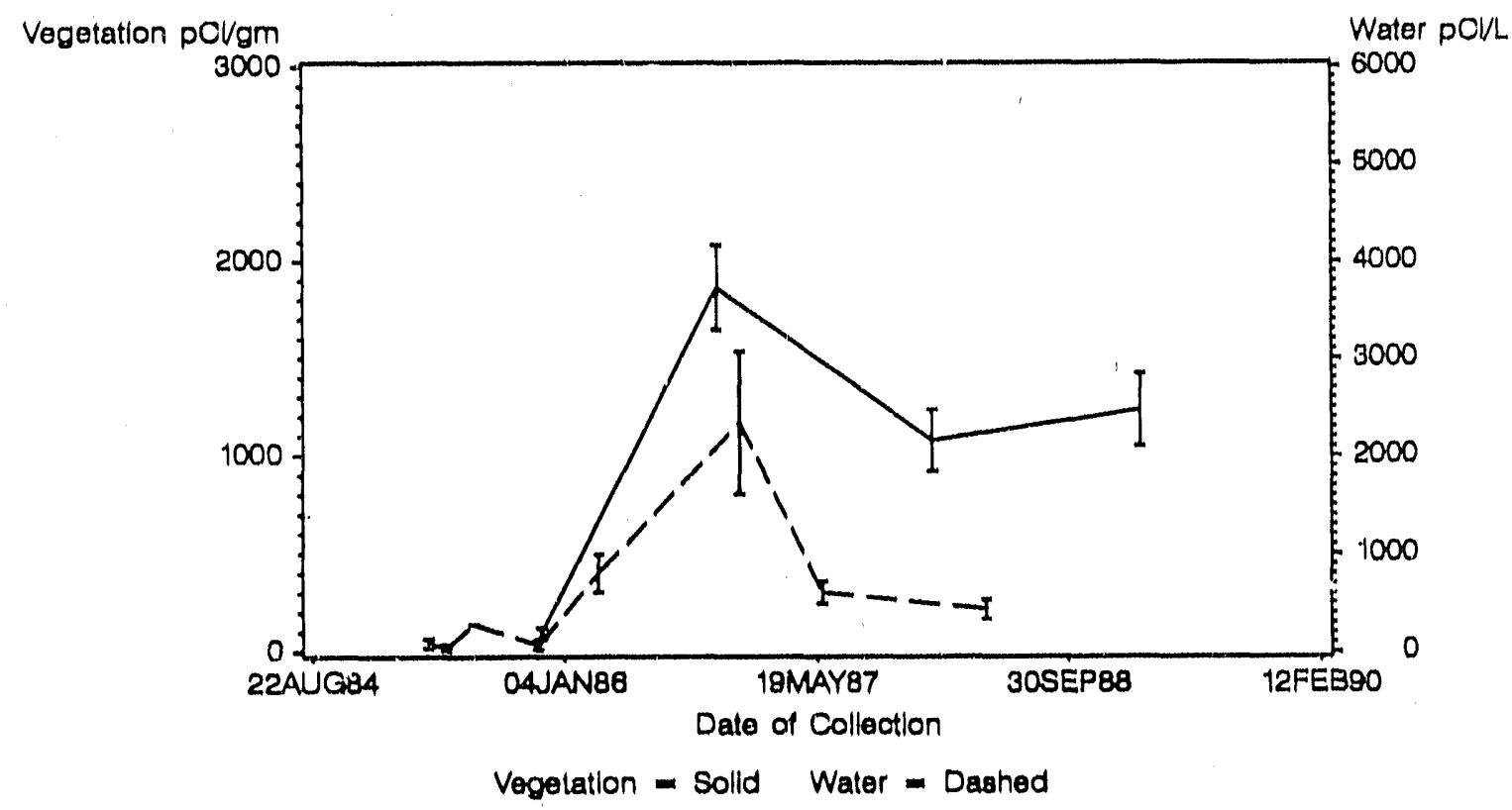

Figure 17. Comparison of 'Tc-99 Concentrations in Sump Water and Vegetation in the Grass Lysimeters (Bars are One Standard Deviation of the Mean). 


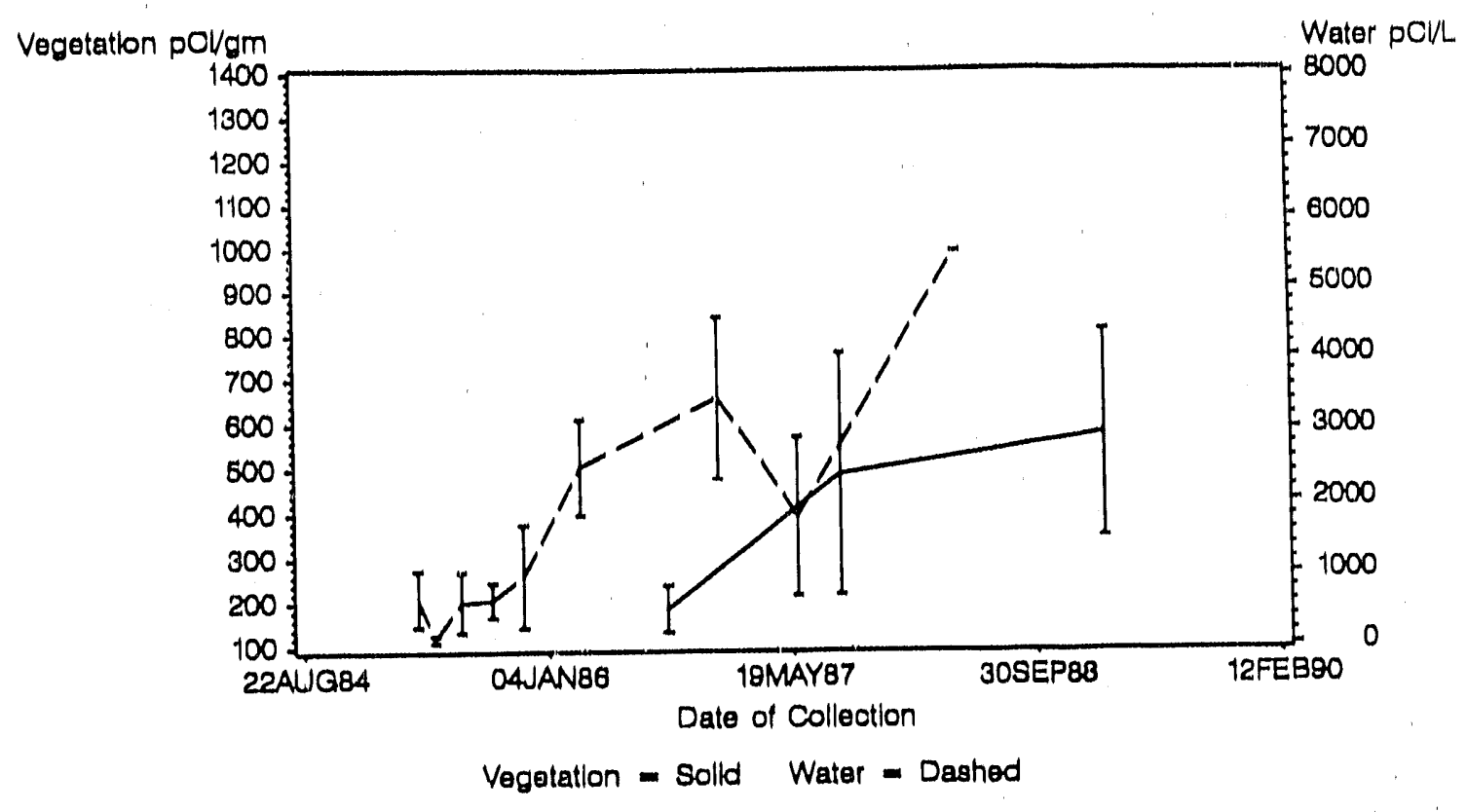

Figure 18. Comparison of Tc-99 Concentrations in Sump Water and Vegetation in the Tree Lysimeters (Bars are One Standard Deviation of the Mean).

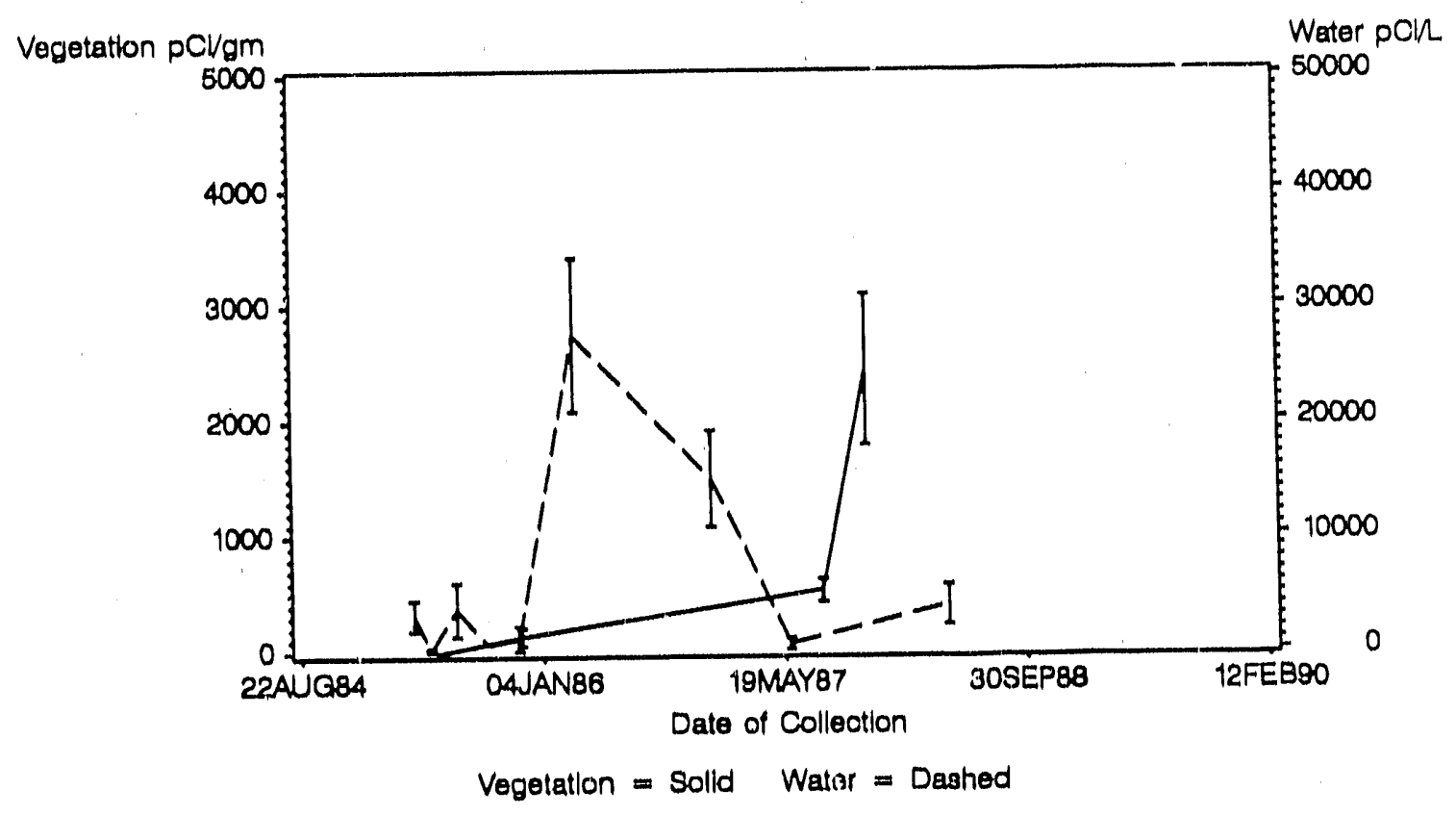

Figure 19. Comparison of Tc-99 Concentrations in Sump Water and Vegetation in the Crop Lysismeters (Bars are One Standard Deviation of the Mean). 
The compartson of the crops indicates that crops were grown in the lysimeters before and after the peak concentration of Tc-99 in the soll water. However, there is still sufficient Tc-99 in the soll water to explain the concentrations found in the vegetation planted in 1987.

\section{Concentration Factors for Tc-99 Uptake from Lysimeter Soil Water}

Since both the soll water and vegetation concentration are available for Tc-99 in the saltstone lysimeters, it is possible to compute the concentration factors for this radionuclide. In order to avoid the ambigulty caused by the lags involved in the measurements, concentration factors were calculated for periods when there was the least change in the soll water concentration. The results are illustrated in Figures 17, 18, 19, and 20 and summarized in Table 6 .

There are two outlying points in the concentration factors calculated for the grass lysimeters. Inspection of the data did not reveal a reason for the behavior of the two lysimeters during the period of measurement. The average concentration factors are given for the grass lysimeters including all of the data and excluding the outlying points (in parenthesis). An outlier also exists in the crop lysimeter data. Inspection of the data indicated that these data were collected at a lysimeter that had recurring drainage problems and had yielded very poor crops. The concentration factors for the crops are shown

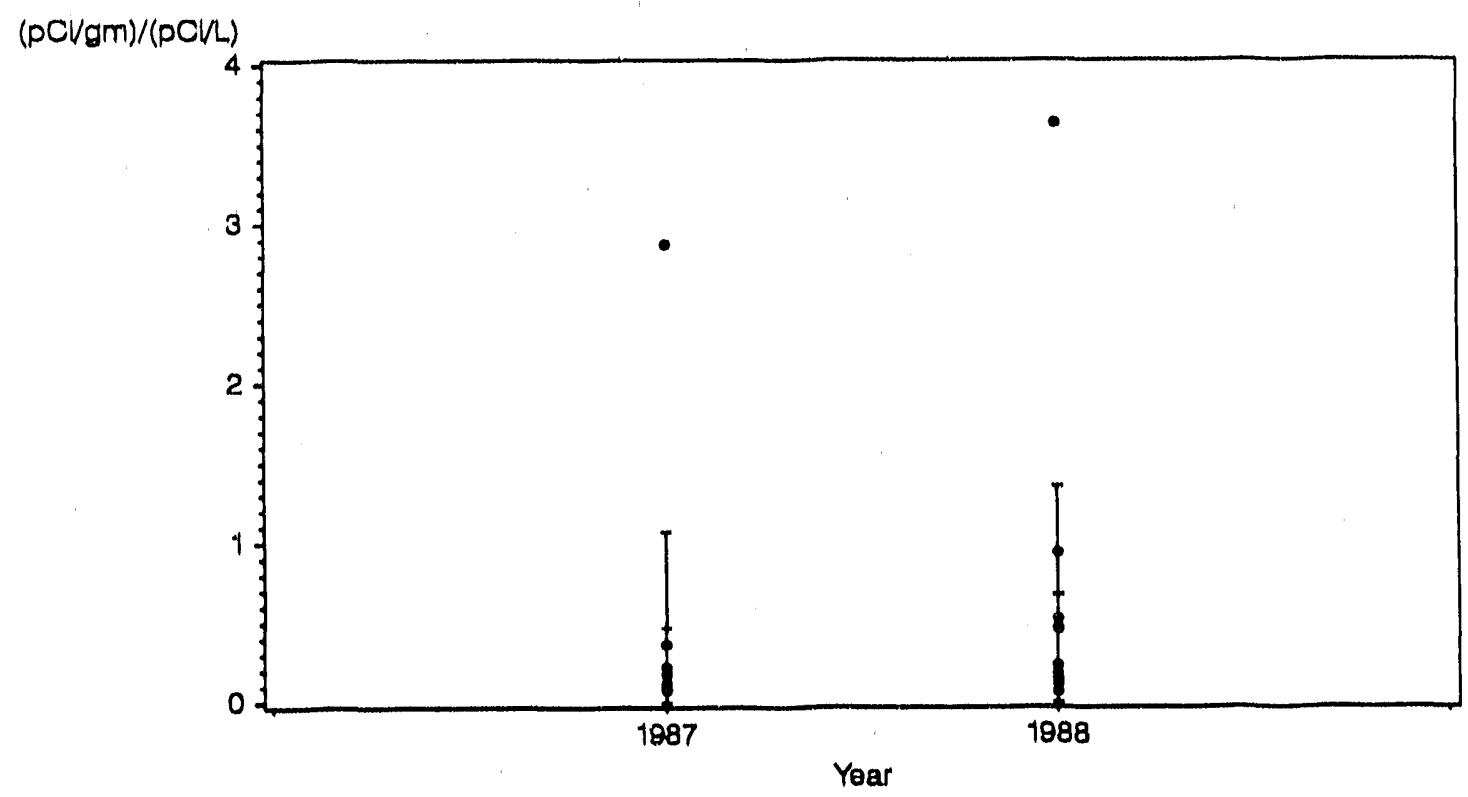

Figure 20. Concentration Uptake Factor for Tc-99 from Sump Water to Grass (Bars are One Standard Deviation of the Mean). 


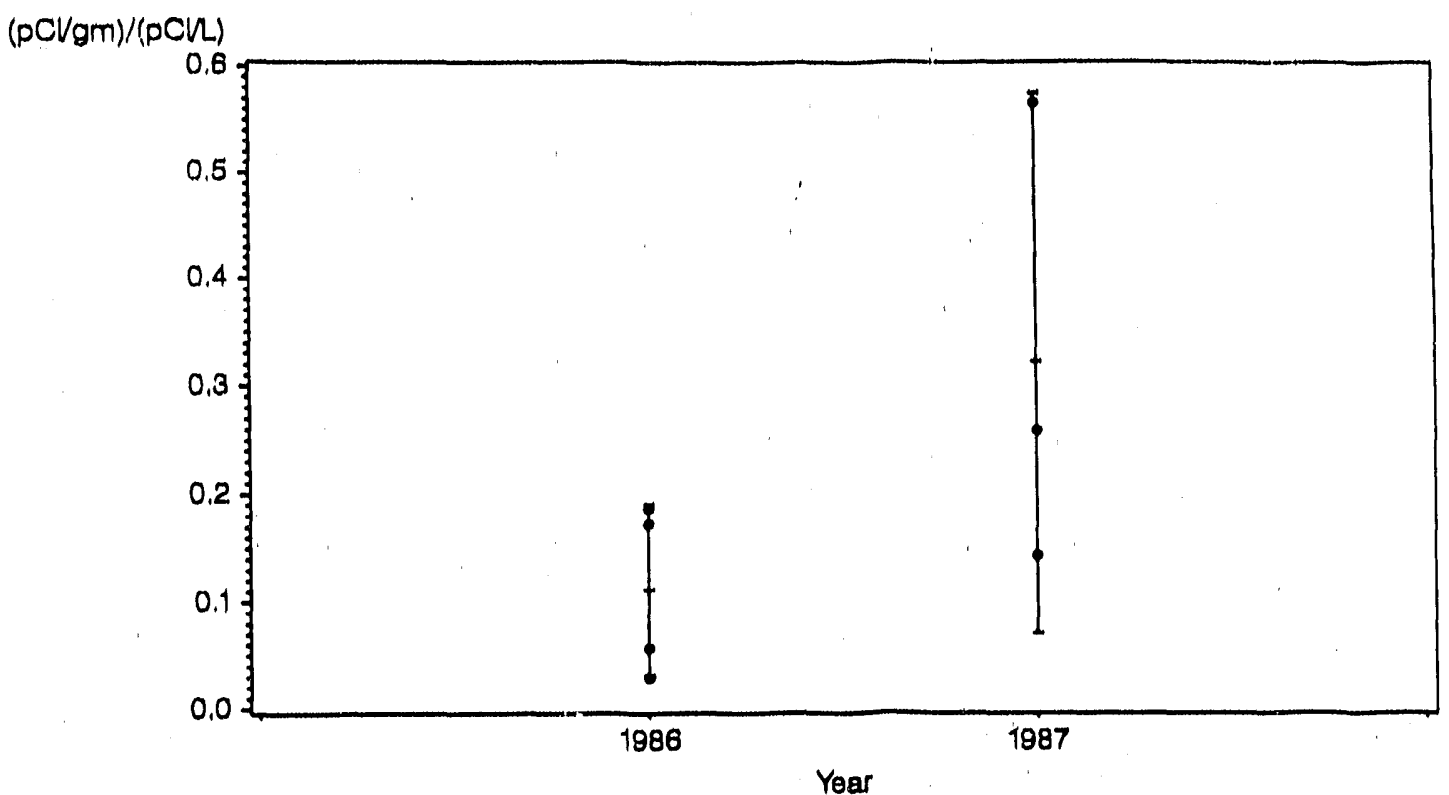

Figure 21. Concentration Uptake Factor for Tc-99 from Sump Water to Trees (Bars are One Standard Deviation of the Mean).

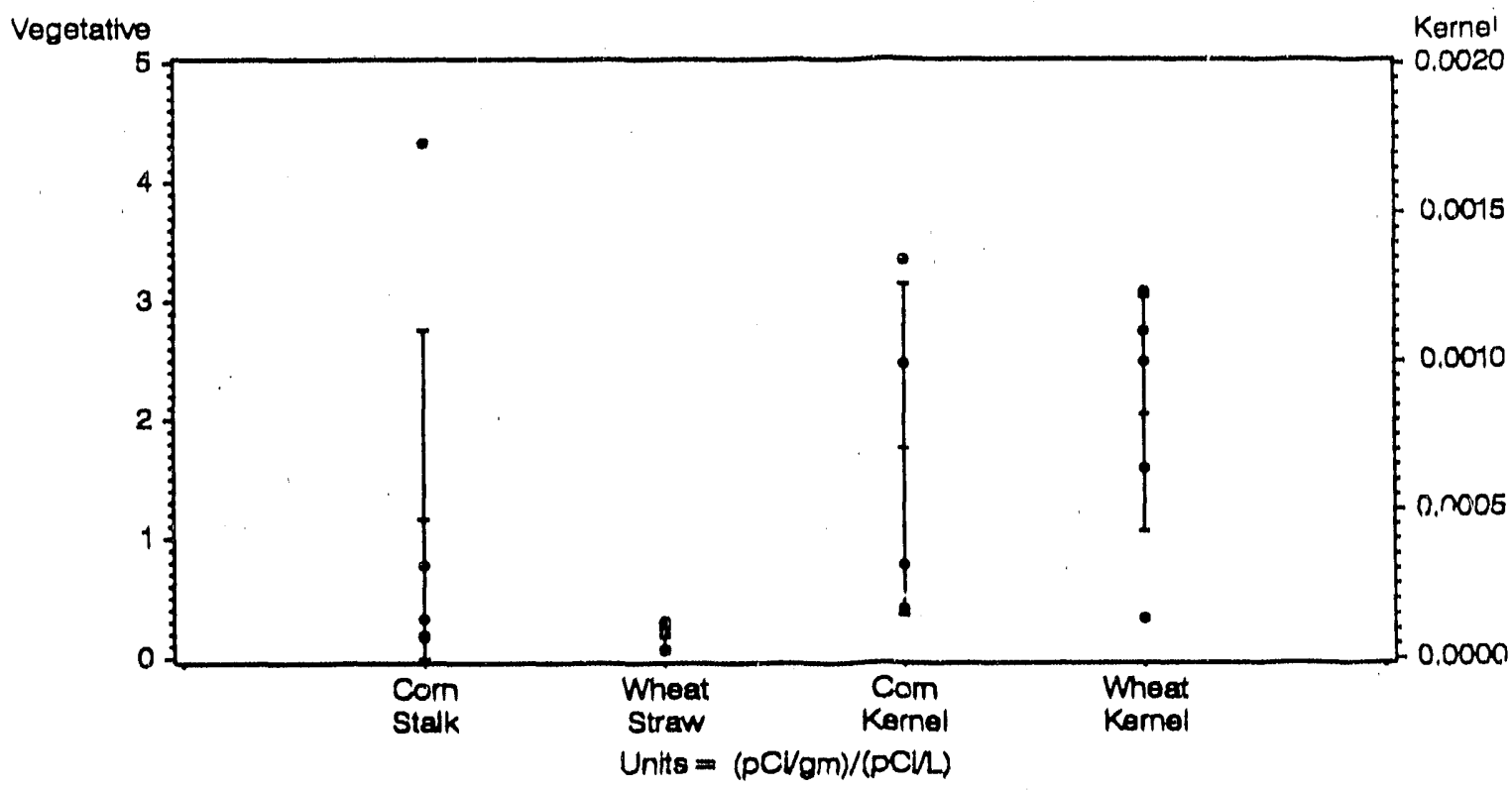

Figure 22. Concentration Uptake Factor for Tc-99 from Sump Water to Vegetation and Seed of Crops (Bars are One Standard Deviation of the Mean). 
with and without inclusion of the data from this lysimeter.

The results indicate that the concentration factors for the vegerative parts of all the species are very similar with average values of between 0.167 and 0.371 (when outliers are removed). The concentration factors for the corn and wheat kernels are very similar to each other but are over two orders of magnitude less than those for the vegetative parts of the plants. These findings have some implication for dose calculation since the edible part of many plants are the seeds. The concentration ratios are in agreement with the findings of other investigators ${ }^{6}$.

Table 6. Mean Ratios of Tc-99 Activity in Vegetation versus Lysimeter Sump Water for Different Vegetation Types in Units of $(\mathrm{pCi} / \mathrm{gm}) /(\mathrm{pCi} / \mathrm{L})$.

Vegetation

Troe

Grass

1987

1988

Trees

1986

1987
Mean

$0.468(0.167)$

$0.677(0.349)$
Standard

Deviation

$0.906(0.094)$

$1.071(0.280)$
Number of

Lusimeters

Crops (all 1987)

Corn Stalk

Wheat Straw

Corn Kernel

0.111

0.323

0.078

0.219

9

10

Wheat Kernel

$1.164(0.371)$
0.183
0.000703
0.000820

$1.789(0.280)$

5

0.107

0.000557

0.000443

4

3

Note: Numbers in parenthesis are the values of the same statistic with a single exceptionally high value removed (see Figures 20 and 22). 


\section{CONCLUSIONS}

The results of this experiment indicate that the primary class of materials moving into the environment from this saltstone formulation are anions in water solution. Tc-99, which has an anionic soluble pertechnetate form, is the only significant element of this type in the saltstone. Other anions measured in the sump water collected from below the soil column in the lysimeters were nitrate and sulfate.

there was no evidence of either heavy metal ontamination of the soil water or uptake of heavy metals by plants growing in the lysimeters.

Small amounts of cesium were taken up from material leaching from the saltstone into the soil. Cs-137 is not found in the lysimeter sumps, as was the case for Tc-99, because cesium is absorbed by the soil near the saltstone blocks in the lysimeters. The concentration difference between the plants grown in control and the saltstone lysimeters was very small and the consequences of this uptake are likewise likely to be small.

Uptake factors were calculated for uptake of Tc-99 from soil water. The results were very similar for the vegetative parts of all of the species grown. The uptake factors calculated for the seed of crops were less by a factor of 100 than the uptake factors for the vegetative parts.

The amount of Tc-99 uptake was not consistently related to the depth of burial of the saltstone. Blocks of saltstone purposely broken at the start of the experiment did release greater amounts of nitrate, sulfate and Tc-99. However, the only significant differences in vegetative uptake found between different treatments was the lower value of the control lysimeters.

The results indicate that the formulation of saltstone used in this experiment will allow uptake of Tc-99 into vegetation that penetrate into the region where the saltstone is buried. The uptake appears to be related to release of the Tc- 99 from the saltstone into the soil water where it is taken up by the plants. Only minor amounts of other radionuclides associated with saltstone were detected in vegetation.

\section{ACKNOWLEDGEMENTS}

The design and supervision of the construction of the Environmental Science Section Lysimeter Facility was done by T.L. Johnson as documented in reference number 1. T.L. Johnson also supervised the collection and analysis of the initial set of vegetation and sump water samples. Later samples were taken by M.W. Lower. R.C. Tuckfield provided valuable consultation on the statistical techniques used to analyze the data. 


\section{References}

1. T.L. Johnson. Lysimeter Study of Vegetation Uptake from Saltstone, Part I: Design, Installation, and Data Collection Plan. DP-1717, E.I. du Pont de Nemours and Company, Savannah River Labortory, Aiken, SC (1986).

2. R. L. Hooker and R. W. Root, Jr. Lysimeter Tests of SRP Waste Forms. DP-1591, E. I. du Pont de Nemours and Company, Savannah River Laboratory, Aiken, SC (1981).

3. S. B Oblath. Defense Waste Lysimeters: 1983-84 Monitoring Report. DPST-84-859, E. I. du Pont de Nemours and Company, Savannah River Laboratory, Aiken, SC (1984).

4. H. C. Wolfe. Large-Scale Demonstration of Disposal of Decontaminated Salt, Part I: Construction, Loading, and Capping of Lysimeters. DPST-84-497, E. I. du Pont de Nemours and Company, Savannah River Laboratory, Aiken, SC (1984).

4. C. M. King and R. W. Root, Jr. "Radionuclide Migration Model for Buried Waste at the Savannah River Plant." Proceedings Waste Management '82 Meeting, Tucson, AZ (1982).

5. S. B. Oblath and C. A. Langton, Comparison of Leach Results from Field and Laboratory Prepared Samples. DPST-85-261, E. I. du Pont de Nemours and Company, Aiken, SC (1985).

6. C.M. Vandecasteele, J.P. Dehut, S. Van Laer, D. Deprins, and C. Myttenaere. " Long-term availability of Tc Deposited on Soil after Accidental Release." Health Physics 57:247-254 (1989). 
Appendix

$-37-$ 
Table A.1 Average Vegetation Radionuclide and Elemental Concentrations in Bermuda Grass (pCi/gm or $\mathrm{mg} / \mathrm{gm}^{*}$ )

By Date of Collection

$\begin{array}{lrrrrrrrr}\text { Date } & \text { Tc.99 } & \text { Cs-137 } & \text { H.3 } & \text { Pu-238 } & \text { Pu.239 } & \text { Sr-90 } & \text { *S } & \text { *TKY } \\ \text { 19Nov85 } & 92 & 0.758 & 1158 & & 0.3667 & 0.450 & 3204 & 10786 \\ \text { 01Nov86 } & 1566 & 0.745 & 1191 & 0.0122 & 0.0044 & 0.361 & . & . \\ \text { 04Jan88 } & 879 & 0.902 & . & 0.0145 & 0.0034 & 0.222 & . & . \\ \text { 16Feb89 } & 995 & 0.378 & 29 & 0.0434 & 0.0180 & 0.219 & . & .\end{array}$

By Treatment (Depth in inches, 19 Nov85 data not included)

$\begin{array}{lrrrrrrrr}\text { Treatment } & \text { Tc-99 } & \text { Cs-137 } & \text { H-3 } & \text { Pu-238 } & \text { Pu-239 } & \text { Sr-90 } & \text { S } & \text { IKN } \\ 06 & 1575 & 0.578 & 598 & 0.0167 & 0.0058 & 0.306 & & \\ 18 & 1420 & 1.127 & 840 & 0.0136 & 0.0053 & 0.273 & . & \\ 36 & 1261 & 0.873 & 460 & 0.0135 & 0.0120 & 0.240 & . & \\ 54 & 1298 & 0.593 & 584 & 0.0452 & 0.0130 & 0.283 & . & \\ \text { Broken@12 } & 1164 & 0.632 & 514 & 0.0131 & 0.0048 & 0.248 & . & \\ \text { Control } & 11 & 0.329 & 692 & 0.0164 & 0.0064 & 0.240 & . & .\end{array}$

By Date of Collection and Saltstone Block Treatment (Depth)

Date/

\begin{tabular}{|c|c|c|c|c|c|c|c|c|}
\hline$\frac{\text { Treatment }}{19 \text { Nov85 }}$ & Tc.-99 & Cs-137 & H.3 & $\mathrm{P}_{\mathrm{u}-238}$ & $\mathrm{Pu} \cdot 239$ & Sr-90 & $\mathbf{S}$ & TKN \\
\hline 06 & 21 & 0.765 & 990 & r. & & 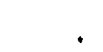 & 3405 & 12850 \\
\hline 18 & 130 & 1.255 & 1250 & . & 0.4600 & & 3160 & 10850 \\
\hline 36 & 72 & 0.580 & 1075 & . & & 0.590 & 3358 & 10200 \\
\hline 54 & 169 & 0.383 & 1270 & . & 0.1800 & 0.320 & 2786 & 12175 \\
\hline Broken@12 & 76 & 1.295 & 1200 & . & . & & 3280 & 9900 \\
\hline Control & 9 & 0.370 & 1050 & & . & 0.570 & 3650 & 7350 \\
\hline \multicolumn{9}{|l|}{ e1Nov86 } \\
\hline 06 & 1760 & 0.489 & 1180 & 0.0012 & 0.0012 & 0.468 & . & \\
\hline 18 & 1835 & 1.601 & 1655 & 0.0021 & 0.0010 & 0.367 & . & \\
\hline 36 & 2010 & 0.795 & 889 & 0.0008 & 0.0012 & 0.352 & . & \\
\hline 54 & 2000 & 0.582 & 1145 & 0.0402 & 0.0122 & 0.338 & . & \\
\hline Broken@12 & 1324 & 0.872 & 995 & 0.0008 & 0.0009 & 0.368 & . & \\
\hline Control & 32 & 0.291 & 1330 & 0.0004 & 0.0024 & 0.296 & . & \\
\hline \multicolumn{9}{|l|}{ 04. $\operatorname{lan} 88$} \\
\hline 06 & 1264 & 0.726 & . & 0.0087 & 0.0019 & 0.234 & . & \\
\hline 18 & 925 & 1.320 & . & 0.0067 & 0.0030 & 0.245 & . & . \\
\hline 36 & 1055 & 1.298 & . & 0.0055 & 0.0027 & 0.249 & . & \\
\hline $\mathrm{BB}$ & 756 & 0.659 & . & 0.0168 & 0.0038 & 0.203 & . & \\
\hline $\mathrm{C}$ & 0 & 0.583 & . & 0.0361 & 0.0059 & 0.202 & . & \\
\hline \multicolumn{9}{|l|}{ 16Feb89 } \\
\hline 06 & 1700 & 0.518 & 16 & 0.0402 & 0.0144 & 0.217 & . & \\
\hline 18 & 1500 & 0.460 & 25 & 0.0320 & 0.0120 & 0.206 & . & \\
\hline 36 & 719 & 0.525 & 30 & 0.0172 & 0.0306 & 0.194 & . & . \\
\hline 54 & 818 & 0.332 & 23 & 0.0899 & 0.0242 & 0.262 & . & \\
\hline Broken@12 & 1412 & 0.364 & 34 & 0.0219 & 0.0096 & 0.173 & . & \\
\hline Control & 0 & 0.113 & 53 & 0.0125 & 0.0110 & 0.221 & . & \\
\hline
\end{tabular}


Table A.2 Average Vegetation Radionuclide and Elemental Concentrations in Trees (pCi/gm or mg/gm*)

By Date

$\begin{array}{lrrrrrrrr}\text { Date } & \text { Tr-92 } & \text { Cs-137 } & \text { H-3 } & \text { Pu-238 } & \text { Pu-239 } & \text { Sr-90 } & \text { S* } & \text { TKN }^{*} \\ \text { 04Sep86 } & 148 & 0.188 & 3296 & 0.0051 & 0.0014 & 0.369 & 554 & 4780 \\ \text { 24Aug87 } & 391 & 0.812 & 1066 & 0.0390 & 0.0059 & 0.205 & 675 & 5725 \\ \text { 16Feb89 } & 482 & 0.296 & 101 & 0.0326 & 0.0153 & 0.207 & . & .\end{array}$

By Treatment (Depth in inches)

$\begin{array}{lrrrrrrrr}\text { Treatment } & \text { Tc.99 } & \frac{\text { Cs-137 }}{36} & \text { H-3 } & \text { Pu-238 } & \text { Pu-239 } & \text { Sr-90 } & \text { S } & \text { TKV } \\ 54 & 380 & 0.358 & 1593 & 0.0354 & 0.0098 & 0.290 & 710 & 5950 \\ \text { Broken@12 } & 356 & 0.313 & 1463 & 0.0186 & 0.0089 & 0.196 & 517 & 5333 \\ \text { C } & 645 & 0.506 & 1630 & 0.0344 & 0.0074 & 0.331 & 850 & 5100 \\ & 0 & 0.649 & 1337 & 0.0199 & 0.0045 & 0.262 & 400 & 4350\end{array}$

By Date Harvested and Treatment (Depth in inches)

\begin{tabular}{|c|c|c|c|c|c|c|c|c|}
\hline $\begin{array}{l}\text { Treatment/ } \\
\text { Date } \\
04 \text { Sen86 }\end{array}$ & TC-92 & Cs. 137 & $\mathrm{H}_{-3}$ & $\mathrm{Pu}_{4238}$ & $\mathrm{P}_{u-232}$ & $\underline{S}-20$ & $\mathbf{S}$ & TKN \\
\hline 36 & 120 & 0.162 & 5120 & 0.0045 & 0.0014 & 0.368 & 620 & 5400 \\
\hline 54 & 138 & 0.116 & 2990 & 0.0036 & 0.0010 & 0.261 & 475 & 4950 \\
\hline Broken@12 & 342 & 0.297 & 3680 & 0.0112 & 0.0028 & 0.698 & 800 & 4700 \\
\hline $\begin{array}{l}\text { C } \\
24 \text { Ang87 }\end{array}$ & 0 & 0.248 & 1700 & 0.0026 & 0.0006 & 0.258 & $4: 0$ & 3900 \\
\hline 36 & 196 & 0.763 & 1050 & 0.0627 & 0.0097 & 0.442 & 800 & 6500 \\
\hline 54 & 738 & 0.572 & 1130 & 0.0186 & 0.0033 & 0.131 & 600 & 6100 \\
\hline Broken@12 & 283 & 0.931 & 1110 & 0.0623 & 0.0092 & 0.159 & 900 & 5500 \\
\hline $\mathrm{C}$ & 1 & 1.220 & 974 & 0.0330 & 0.0039 & 0.162 & 400 & 4800 \\
\hline 16Feb89 & & & & & & & & \\
\hline 36 & 602 & 0.253 & 102 & 0.0373 & 0.0140 & 0.175 & . & \\
\hline 54 & 191 & 0.251 & 101 & 0.0337 & 0.0224 & 0.195 & . & \\
\hline Broken@12 & 1310 & 0.291 & 100 & 0.0297 & 0.0103 & 0.137 & . & \\
\hline C & 1 & 0.479 & 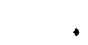 & 0.0240 & 0.0089 & 0.365 & . & \\
\hline
\end{tabular}


Table A.3 Average Vegetation Radionuclide and Elemental Concentrations in Crop Vegetative Parts (pCi/gm or $\mathrm{mg} / \mathrm{gm}^{*}$ )

By Date Harvested

\begin{tabular}{|c|c|c|c|c|c|c|c|c|}
\hline Date & Type & Tc-22 & Cs.137. & $\mathbf{P}_{v_{-}-238}$ & $P_{t-239}$ & Sr -90 & $\mathbf{S}^{*}$ & TKN" \\
\hline 12Dec84 & Soybean & & 0.560 & 0.0833 & 0.0600 & 2.497 & 2214 & 12536 \\
\hline 06Jun85 & Wheat & 1 & 3.693 & 0.2100 & 0.1250 & & 2054 & 10507 \\
\hline 19Nov85 & Soybean & 112 & 0.580 & 0.0800 & 0.0900 & 1.540 & 1977 & 51863 \\
\hline 03Aug87 & Wheat & 396 & 0.513 & 0.0000 & 0.0000 & 0.239 & 0 & 0 \\
\hline 02 Nov87 & Corn & 1835 & 0.985 & 0.1012 & 0.0203 & 0.472 & 2717 & 13617 \\
\hline
\end{tabular}

By Treatment(Depth in inches)

\begin{tabular}{lrrrrrrr} 
Treatment & Tr.99 & Cs-137 & Pu-238 & Pu-239 & Sr-90 & S & TKN \\
\hline 18 & 1331 & 1.028 & 0.0296 & 0.0223 & 0.236 & 2220 & 21740 \\
36 & 1350 & 1.139 & 0.3778 & 0.0603 & 0.479 & 2918 & 27050 \\
Broken@12 & 360 & 0.753 & 0.1089 & 0.0765 & 0.717 & 1677 & 32388 \\
C & 19 & 1.447 & 0.0100 & 0.0031 & 0.403 & 1650 & 24229
\end{tabular}

By Date Harvested and Treatmen:(Depth in inches)

Treatment/

Date$$
18
$$

36

Broken@12

C

26.Jun85/Wheat

18

36

Broken@12

C

19Nov85/Soybean

-18
36

36

Broken@12

C

23Aug87/Wheat

18

36

Broken@12

C

02Nor87/Corn

18

36

Broken@12

C
T

T. 99

\begin{tabular}{rr} 
Cs -137 & Pu-2.38 \\
\hline 0.550 & 0.0800 \\
. & 0.0800 \\
0.570 & 0.0900 \\
$\cdot$ & $\cdot$ \\
& 0.0800 \\
5.080 & $\circ$ \\
. & 0.3400
\end{tabular}

$\mathrm{Pu}_{\mathrm{N}-239}$

Sr-90

0.0600

0.0600

3.700

2.900

1.800

1.080

0.0600

0.1900

3.000

$230 \quad 0.770$

141 $\quad 0.660$

26

50

0.880

0.255

\section{3}

580

359

2

1.230

0.188

0.634

0.204

0.0000

$\begin{array}{ll}1.057 & 0.0044 \\ 0.597 & 0.3778\end{array}$

0.597

0.809

0.3778
0.0077

$1.970 \quad 0.0150$
.

$$
\begin{array}{rrrr}
. & . & 2273 & 44500 \\
0.0900 & 1.540 & 1618 & 51550 \\
. & . & 2073 & 52400 \\
& & & 59000
\end{array}
$$

0.206

0.354

0.182

0.0000

0.216

0.0034

0.0603

0.0129

0.0046

$\begin{array}{rrr}0.266 & 3100 & 1700 \\ 0.605 & 3200 & 14500 \\ 0.428 & 2200 & 19000 \\ 0.590 & 2300 & 16000\end{array}$


Table A.4. Average Vegetation Radionuclide and Elemental Concentrations in Crop Seeds (pCi/gm or mg/gm*)

By Date of Harvest

$\begin{array}{llrrrrrrr}\text { Date } & \text { Type } & \text { Tc.99 } & \text { Cs.137 } & \text { Pu-238 } & \text { Pu-239 } & \text { Sr.90 } & \text { S* } & \text { TKN* } \\ \text { 21Nov84 } & \text { Soybean } & 0.0 & 0.115 & 0.8950 & 0.4750 & 0.510 & 2711 & 52500 \\ \text { O6Jun85 } & \text { Wheat } & & & .0550 & 0.0500 & 0.205 & 1125 & 18357 \\ \text { 03Aug87 } & \text { Wheat } & 2.0 & 0.159 & 0.0003 & 0.0001 & 0.056 & 2013 & 22500 \\ \text { 02Nov87 } & \text { Corn } & 1.8 & 0.088 & 0.0002 & 0.0002 & 0.003 & . & \text {. }\end{array}$

By Treatment (Depth in Inches)

$\begin{array}{lrrrrrrr}\text { Treatment } & \text { Tc.92 } & \text { Cs.137 } & \text { Pu-238 } & \text { Pu-239 } & \text { Sr-90 } & \text { S } & \text { TKN } \\ 18 & 4.6 & 0.169 & 0.0004 & 0.0001 & 0.032 & 1850 & 22000 \\ 36 & 1.5 & 0.080 & 0.0001 & 0.0001 & 0.030 & 1800 & 23500 \\ \text { Broken@ 12 } & 2.1 & 0.160 & 0.0001 & 0.0001 & 0.024 & 2150 & 26000 \\ \text { C } & 0.1 & 0.061 & 0.0004 & 0.0002 & 0.031 & 2250 & 18500\end{array}$

By Date of Harvest and Treatment (Depth in Inches)

Treatment

\begin{tabular}{|c|c|c|c|c|c|c|c|}
\hline \multicolumn{8}{|c|}{$\begin{array}{l}\text { Date } \\
21 \text { Nov84/Sorbean } \mathrm{Tc}-99\end{array}$} \\
\hline .18 & . & 0.130 & & 0.4500 & 1.100 & 2580 & 60000 \\
\hline 36 & • & & & 0.1700 & 0.190 & 2490 & 50000 \\
\hline Broken@12. & & 0.3200 & 0.2500 & & 2610 & 50000 & \\
\hline $\mathrm{C}$ & 0.0 & 0.100 & 1.4700 & 1.0300 & 0.240 & 3165 & 50000 \\
\hline 18 & . & . & . & & . & 1250 & 202.50 \\
\hline 36 & . & & & 0.0500 & & 1070 & 16800 \\
\hline Broken@12. & . & 0.0600 & 0.0500 & 0.180 & 1038 & 19000 & \\
\hline $\mathrm{C}$ & . & & 0.0500 & 0.0500 & 0.230 & 1143 & 17700 \\
\hline \multicolumn{8}{|c|}{ 03Aug87/Wheat } \\
\hline 18 & 4.2 & 0.219 & 0.0005 & 0.0001 & 0.060 & 1850 & 22000 \\
\hline 36 & 1.4 & 0.106 & 0.0001 & 0.0001 & 0.058 & 1800 & 23500 \\
\hline Broken@12 & 2.5 & 0.207 & 0.0001 & 0.0001 & 0.046 & 2150 & 26000 \\
\hline C & 0.0 & 0.048 & 0.0006 & 0.0000 & 0.060 & 2250 & 18500 \\
\hline \multicolumn{8}{|l|}{22 Nov87/Corn } \\
\hline 18 & 5.5 & 0.118 & 0.0002 & 0.0002 & 0.005 & . & \\
\hline 36 & 1.6 & 0.055 & 0.0002 & 0.0001 & 0.001 & . & \\
\hline Broken@12 & 1.7 & 0.113 & 0.0001 & 0.0000 & 0.002 & . & . \\
\hline $\mathrm{C}$ & 0.3 & 0.068 & 0.0003 & 0.0004 & 0.003 & . & . \\
\hline
\end{tabular}


Table A.5 Average Nonradioactive Lysimeter Sump Water Concentrations for Grass Lysimuters (mg/L).

\begin{tabular}{|c|c|c|c|c|c|c|c|c|c|c|c|}
\hline \multicolumn{12}{|l|}{ By Year } \\
\hline$\frac{\text { Year }}{1984}$ & $8 . \frac{\mathrm{DH}}{484}$ & $\frac{222}{222}$ & $\frac{\mathrm{NO}_{2}}{0.01}$ & $\mathrm{NO}_{3}$ & $\frac{\operatorname{lng}}{0.84}$ & $\frac{304}{23.8}$ & Cr & $\frac{H}{0.0002}$ & 0.13 & 12 & 9 \\
\hline 1985 & 8.019 & 352 & 2.00 & 14 & 0.72 & 15.9 & & 0.0003 & 5.09 & $0.2(n)$ & 109 \\
\hline 1986 & 7.743 & 1182 & 2.29 & 114 & 1.06 & 25.0 & . & 0.0002 & 0.45 & 0.140 & 79 \\
\hline 1987 & 7.551 & 1097 & 1.71 & 99 & 0.95 & 33.4 & . & 0.0006 & & 0.692 & 43 \\
\hline 1988 & 7.835 & 982 & 0.83 & 44 & 0.58 & 41,0 & . & 0.0014 & & 0.065 & 32 \\
\hline 1989 & 7.758 & 1015 & 1.03 & 63 & 0.84 & 85.6 & . & 0.0003 & . & 0.060 & 38 \\
\hline \multicolumn{12}{|l|}{ By Treatment } \\
\hline Year & $\mathrm{DH}$ & Cond & $\mathrm{NO}$ & $\mathrm{NO}_{3}$ & TKN & $\mathrm{SO}_{4}$ & $\mathrm{Cr}$ & $\mathrm{Hg}$ & al & B & No. Obs \\
\hline 06 & 7.777 & 594 & 0.24 & 27 & 0.66 & 18.3 & & 0.0003 & 0.15 & 0.084 & 46 \\
\hline 18 & 7.773 & 748 & 1.02 & 51 & 0.46 & 22.3 & . & 0.0002 & 23.30 & & 45 \\
\hline 36 & 7.787 & 877 & 2.00 & 70 & 0.68 & 25.6 & . & 0.0005 & 0.14 & 0.101 & 46 \\
\hline 54 & 7.901 & 728 & 0.78 & 51 & 1.12 & 26.1 & . & 0.0004 & 0.87 & 0.058 & 80 \\
\hline Broken@12 & 8.240 & 1755 & 6.23 & 164 & 0.55 & 74.3 & . & 0.0002 & 5.77 & 0.108 & 46 \\
\hline Control & 7.563 & 225 & 0.01 & 0 & 1.03 & 9.9 & . & 0.0009 & 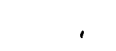 & . & 47 \\
\hline \multirow{2}{*}{\multicolumn{12}{|c|}{$\begin{array}{l}\text { By Year and Treatment } \\
\text { Treatment }\end{array}$}} \\
\hline & & & & & & & & & & & \\
\hline$\frac{\text { Year }}{1984}$ & $\mathrm{pH}$ & Cond & $\mathrm{NO}_{2}$ & $\mathrm{NO}_{3}$ & TKN & SO & $\mathrm{Cr}$ & HI & Al & B & No.Obs \\
\hline \multicolumn{12}{|l|}{1984} \\
\hline 06 & 9.630 & 401 & 0.01 & 0 & 0.70 & 8.2 & . & 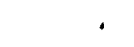 & 0.15 & . & 1 \\
\hline 18 & 8.220 & 205 & 0.00 & 0 & 0.63 & 31.7 & . & . & & . & 2 \\
\hline 36 & 8.120 & 188 & 0.01 & 0 & 0.32 & 23.4 & . & & 0.12 & . & 2 \\
\hline 54 & 8.267 & 231 & 0.01 & 0 & 1.33 & 35.2 & .. & 0.0002 & 0.13 & . & 3 \\
\hline Broken@12 & 9.250 & 116 & 0.00 & 0 & 0.99 & 1.4 & . & 0.0002 & & . & 1 \\
\hline \multicolumn{12}{|l|}{1985} \\
\hline 06 & 7.935 & 333 & 0.10 & 7 & 0.63 & 14.1 & . & 0.0004 & & • & 17 \\
\hline 18 & 7.713 & 266 & 0.01 & 2 & 0.41 & 17.2 & . & 0.0002 & 23.30 & . & 15 \\
\hline 36 & 7.759 & 354 & 0.05 & 7 & 0.31 & 21.2 & . & 0.0002 & 0.15 & . & 14 \\
\hline 54 & 8.046 & 301 & 0.16 & 12 & 1.07 & 14.1 & : & 0.0003 & 1.40 & & 15 \\
\hline Broken@12 & 8.654 & 732 & 11.10 & 50 & 0.63 & 21.5 & . & 0.0003 & 5.77 & 0.200 & 17 \\
\hline Control & 7.887 & 130 & 0.01 & 0 & 0.81 & 8.8 & . & 0.0004 & & & 15 \\
\hline \multicolumn{12}{|l|}{1285} \\
\hline 06 & 7.550 & 687 & 0.40 & 56 & 0.43 & 12.2 & . & 0.0002 & ' & - & 13 \\
\hline 18 & 7.821 & 1261 & 3.06 & 118 & 0.57 & 29.8 & . & . & . & - & 10 \\
\hline 36 & 7.744 & 929 & 3.39 & 76 & 1.89 & 26.4 & . & & & . & 11 \\
\hline 54 & 7.877 & 808 & 1.17 & 59 & 1.66 & 25.2 & . & 0.0002 & 0.45 & & 11 \\
\hline Broken@12 & 7.969 & 3487 & 5.96 & 418 & 0.29 & 40.1 & . & & . & 0.140 & 12 \\
\hline $\begin{array}{l}\text { Control } \\
1987\end{array}$ & 7.424 & 234 & 0.01 & 0 & 0.98 & 16.3 & . & 0.0001 & . & . & 12 \\
\hline 06 & 7.453 & 519 & 0.31 & 37 & 0.83 & 15.2 & . & 0.0004 & . & 0.084 & 6 \\
\hline 18 & 7.523 & 976 & 0.27 & 79 & 0.43 & 9.4 & • & & . & & 6 \\
\hline 36 & 7.613 & 1528 & 4.53 & 152 & 0.31 & 26.5 & . & 0.0006 & . & 0.101 & 7 \\
\hline 54 & 7.611 & 1349 & 1.14 & 125 & 0.33 & 25.9 & . & 0.0007 & . & . & 6 \\
\hline Broken@12 & 7.852 & 1994 & 2.81 & 189 & 0.39 & 129.0 & . & & . & . & 6 \\
\hline Control & 7.290 & 254 & 0.00 & 0 & 2.12 & 5.4 & . & 0.0005 & . & . & 8 \\
\hline \multicolumn{12}{|l|}{1988} \\
\hline 06 & 7.772 & 1316 & 0.09 & 8 & 0.80 & 31.1 & & r & ‘ & r. & 5 \\
\hline 18 & 7.792 & 835 & 0.51 & 44 & & 16.4 & & & . & . & 6 \\
\hline 36 & 7.972 & 1162 & 2.26 & 95 & 0.38 & 32.7 & & 0.0005 & . & . & 6 \\
\hline 54 & 7.960 & 1158 & 0.67 & 74 & 0.34 & 40.2 & . & & . & & 5 \\
\hline Broken@12 & 8.148 & 1293 & 0.93 & 44 & 1.08 & 146.5 & & 0.0002 & . & 0.065 & 4 \\
\hline
\end{tabular}


Table A.6 Averge Nonradioactive Lysimeter Sump Water Concentrations for Tree Lysimeters (mg/L).

By Year

\begin{tabular}{|c|c|c|c|c|c|c|c|c|c|c|c|}
\hline Year & $\mathrm{DH}$ & Cand & $\mathrm{NO}_{2}$ & $\mathrm{NO}_{3}$ & IKN & $\mathrm{SO}$ & $\mathrm{Cr}$ & $\mathrm{Hg}$ & Al & B. & $\mathrm{No}, \mathrm{Obs}$ \\
\hline 1984 & 7.58 .5 & 215 & 0.01 & 0 & 0.28 & 10.5 & & $0.0 \overline{001}$ & $0 . \overline{14}$ & & 2 \\
\hline 1985 & 8.660 & 543 & 3.77 & 36 & 1.50 & 13.8 & & 0.0003 & 1,44 & . & 68 \\
\hline 1986 & 8.281 & 915 & 2,33 & 98 & 0.80 & 29.7 & & 0.0004 & 1.21 & & 42 \\
\hline 1987 & 7.686 & 779 & 1,96 & 58 & 0.62 & 29.5 & & 0.0009 & , & 0.054 & 14 \\
\hline 1988 & 8.360 & 769 & 0.02 & 5 & 1,24 & 21.5 & & • & . & & 1 \\
\hline 1989 & 7.800 & 743 & 0.58 & 67 & . & 50.1 & . & . & . & & 1 \\
\hline
\end{tabular}

By Treatment

$\begin{array}{lrrrrrrrrrrr}\text { Treatment } & \mathbf{p H} & \text { Cond } & \frac{\text { NO }}{2} & \text { NO } & \text { TKN } & \text { SO } & \text { Cr } & \text { Htg } & \text { Al } & \text { B } & \text { No.Obs } \\ 36 & 7.936 & 662 & 2.43 & 50 & 1.25 & 14.7 & .0 .0004 & 0.47 & 0.054 & 47 \\ 54 & 8.441 & 594 & 2.47 & 40 & 1.06 & 15.1 & .0 .0008 & 1.73 & . & 41 \\ \text { Broken@12 } & 8.345 & 1500 & 8.40 & 138 & 0.47 & 66.3 & .0 .0004 & 0.24 & . & 19 \\ \text { Control } & 9.428 & 201 & 0.33 & 0 & 1.27 & 5.9 & .0 .0002 & 1.87 & . & 21\end{array}$

By Year and Treatment

Year/

\begin{tabular}{|c|c|c|c|c|c|c|c|c|c|c|c|}
\hline$\frac{\text { Treament }}{1984}$ & $\mathrm{DH}$ & Cond & $\mathrm{NO}_{2}$ & $\mathrm{NO}_{3}$ & IKN & SO. & $\mathrm{Cr}$ & Hg & Al & B & No. $\mathrm{Obs}_{\mathrm{s}}$ \\
\hline $\begin{array}{l}36 \\
1985\end{array}$ & 7.585 & 215 & 0.01 & 0 & 0.28 & 10.5 & & 0.0001 & 0.14 & • & \\
\hline 36 & 8.163 & 462 & 3.00 & 24 & 1.68 & 11.9 & . & 0.0001 & 0.51 & & \\
\hline 54 & 8.764 & 359 & 2.18 & 10 & 1.28 & 10.6 & . & 0.0003 & 2.16 & . & \\
\hline Broken@12 & 8.286 & 1493 & 13.03 & 138 & & 34.2 & . & 0.0007 & 0.27 & . & \\
\hline $\begin{array}{l}\text { Control } \\
1986\end{array}$ & 9.777 & 248 & 0.22 & 0 & 1.56 & 6.6 & . & 0.0002 & 1.82 & . & \\
\hline 36 & 7.739 & 1016 & 1.92 & 105 & 0.94 & 19.7 & . & 0.0002 & & . & \\
\hline 54 & 8.179 & 827 & 2.98 & 72 & 0.78 & 19.9 & & 0.0006 & 0.56 & . & \\
\hline Broken@12 & 8.546 & 1673 & 3.79 & 160 & 0.53 & 95.5 & . & 0.0002 & 0.16 & . & \\
\hline $\begin{array}{l}\text { Control } \\
1987\end{array}$ & 9.307 & 132 & 0.38 & 0 & 0.83 & 3.6 & . & . & 1.96 & . & \\
\hline 36 & 7.537 & 764 & 2.12 & 46 & 0.65 & 14.5 & . & 0.0007 & . & 0.054 & \\
\hline 54 & 7.758 & 978 & 2.18 & 83 & 0.20 & 21.7 & & 0.0016 & . & . & \\
\hline Broken@12 & 8.080 & 1120 & 2.09 & 58 & 0.21 & 198.0 & & 0.0003 & . & . & \\
\hline $\begin{array}{l}\text { Control } \\
1988\end{array}$ & 7.760 & 158 & 0.87 & 1 & 1.17 & 9.9 & . & 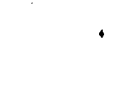 & . & . & \\
\hline $\begin{array}{l}36 \\
1989\end{array}$ & 8.360 & 769 & 0.02 & 5 & 1.24 & 21.5 & . & . & . & . & \\
\hline Broken@12 & 7.800 & 743 & 0.58 & 67 & & 50.1 & & • & . & . & \\
\hline
\end{tabular}


Table A.7. Average Nonradioactive Lysimeter Sump Water Concentrations for Crop Lysimeters (mg/L).

By Year

Year

$\begin{array}{rrrr}1984 & 7.733 & 375 & 0.11 \\ 1985 & 7.559 & 962 & 0.53 \\ 1986 & 7.571 & 1810 & 1.37 \\ 1987 & 7.219 & 960 & 0.19 \\ 1988 & 7.610 & 1271 & 0.28\end{array}$

NO, TKN SO $\mathrm{Cr} \quad \mathrm{Hg}$

\begin{tabular}{|c|c|}
\hline & 0.87 \\
\hline 571.52 & 33.9 \\
\hline 1711.35 & 78. \\
\hline 441.64 & 84 \\
\hline 490.70 & 16 \\
\hline
\end{tabular}

$\begin{array}{rrr}\text { a.d } & \text { B } & \text { No. Obs } \\ 5.71 & 0.213 & 14 \\ 0.286 & 75 & \\ : & 53 & \\ : & 16 & \\ 1 & 17 & \end{array}$

By Treatment

Year.

oH Sond NO, NO, IKN SO $\mathrm{Cr}$ Hr

$\begin{array}{rrr}\text { Al } & \text { B } & \text { No. Obs } \\ & & \\ 0.69 & 0.253 & 52 \\ 0.74 & 0.250 & 53 \\ 10.49 & 0.218 & 46 \\ 4.97 & 0.287 & 45\end{array}$

$\begin{array}{lr}18 & 7.482 \\ 36 & 7.563 \\ \text { Broken@12 } & 7.500 \\ \text { Control } & 7.582 \\ & \\ \text { By Year and Treatment } \\ \text { Year }\end{array}$

$\frac{\text { Year }}{1984}$

18

$36 \quad 7.760$

Broken@12

Control

7.657

$1075 \quad 0.49$

$71 \quad 2.28$

2.28
1.10

$87.3 \quad 0.076 \quad 0.0002$

50.7

$0.113 \cdot 0.0004$ 180

1.25

$\begin{array}{rrr}151.4 & 0.113 & 0.0004 \\ 25.9 & 0.077 & 0.0008\end{array}$

$\begin{array}{rr}2.242 & 0.68 \\ 504 & 0.06\end{array}$

0.77

25.9

$\begin{array}{lll}0.077 & 0.0008\end{array}$

$\begin{array}{ll}4.97 & 0.287\end{array}$

No. Obs
1285

18

36

Broken@12

Control

1986

18

36

Broken@12

Control

1987

18

36

Control

1288

18
36

Broken@12

Control
NO

0.03

0.00

$359 \quad 0.35$

7.665

$278 \quad 0.01$

$\begin{array}{lll}7.581 & 1049 & 0.74\end{array}$

$\begin{array}{rrr}7.569 & 572 & 0.37\end{array}$

7.485

7.594

1775

494

7.535

7.678

1553

0.43

4.00

0.72

0.02

7.636

526

7.070

7.236

$681 \quad 0.21$

$1432 \quad 0.25$

$\begin{array}{ll}1275 & 0.07\end{array}$

$560 \quad 0.16$

7.383

7.367

7.626

$\begin{array}{ll}887 & 0.19\end{array}$

$1316 \quad 0.41$

$2373 \quad 0.33$

$495 \quad 0.00$

7.603
NQ, TKN

$\begin{array}{rrr}11 & 0.82 & 30.6 \\ 0 & 0.49 & 8.0 \\ 4 & 1.57 & 25.2\end{array}$

Cr $\mathrm{Ha}$

0.0760 .0001

. 0.0002

$0 \quad 0.73$

9.3

$0.113 \quad 0.0002$

$0.077 \quad 0.0008$

$62 \quad 3.80$

$24 \quad 1.06$

55.6

25.9

0,0002

.0 .0002

.0 .0006

. 0.0011

17.3

0.0001

$\begin{array}{lll}150 & 1.59 & 93.6\end{array}$

$\begin{array}{lll}154 & 1.56 & 36.9\end{array}$

$\begin{array}{lll}381 & 1.78 \quad 152.9\end{array}$

$0.87 \quad 34.1$

.

. 0.0002

al

$\begin{array}{ll}1.68 & 0.230\end{array}$

$\begin{array}{lll}22 & 3.53 & 111.2\end{array}$

$\begin{array}{llr}95 & 0.20 & 59.7\end{array}$

$\begin{array}{lll}46 & 0.20 & 185.5\end{array}$

0.0008

. 0.0003

. 0.0009

$10.49 \quad 0.235$

$4.97 \quad 0.175$

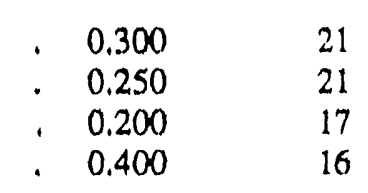

0.28

0.74

$0.71 \quad 31.4$

$\begin{array}{rrr}31 & 1.03 & 158.9 \\ 71 & 0.62 & 94.9\end{array}$

$\begin{array}{llll}85 & 0.46 & 94.9\end{array}$

$\begin{array}{lll}3 & 0.49 & 36.8\end{array}$

0.49

.
.
.0 .0003
0.0002

0.19

4
2
4
4

21
21
17
16

13
14
13
13

5
5
2
4
4
4
4
4
4

\begin{abstract}
36.8
\end{abstract}


Table A.8 Average Radinactive Isotope Concentration in Grass Lysimeter Sump Water (pCi/L) By Year

\begin{tabular}{|c|c|c|c|c|c|}
\hline & Year & Tc. .92 & $5+.90$ & $\mathbf{H} \cdot \mathbf{3}$ & No, Obs \\
\hline & $\overline{1985}$ & 553 & 4.233 & 97 & 36 \\
\hline & 1986 & 11024 & 0.792 & 337 & 20 \\
\hline & 1987 & 5281 & 0.494 & 329 & 12 \\
\hline & 1988 & 3626 & 0.315 & 262 & 12 \\
\hline \multicolumn{6}{|c|}{ By Treatment } \\
\hline & Treatment & $\operatorname{Tc} 92$ & Sr.90 & $\mathrm{H} \cdot \mathbf{3}$ & $\mathrm{No}, \mathrm{Obs}$ \\
\hline & 06 & $\overline{2964}$ & $\overline{0.430}$ & 208 & 14 \\
\hline & 18 & 10040 & 0.520 & 256 & 13 \\
\hline & 36 & 5952 & 0.298 & 197 & 10 \\
\hline & 54 & 1633 & 0.830 & 174 & 17 \\
\hline & Broken@12 & 646 & 2.095 & 277 & 14 \\
\hline & Control & 22 & 1.461 & 189 & 12 \\
\hline \multicolumn{6}{|c|}{ By Year and Treatment } \\
\hline \multirow{7}{*}{$\frac{\text { Year }}{1985}$} & Treatment & Tc.99 & Sr-90 & $H_{-3}$ & $\mathrm{No}, \mathrm{Obs}$ \\
\hline & 06 & 1334 & . & 86 & 6 \\
\hline & 18 & 5 & . & 105 & 5 \\
\hline & 36 & 394 & & 92 & 4 \\
\hline & 54 & 58 & 2,000 & 87 & 10 \\
\hline & Broken@12 & 1362 & 4.000 & 146 & 7 \\
\hline & Control & 47 & 9.400 & 48 & 4 \\
\hline \multicolumn{6}{|l|}{1986} \\
\hline & 06 & 5040 & 0.353 & 422 & 4 \\
\hline & 18 & 26773 & 0.656 & 413 & 4 \\
\hline & 36 & 11830 & 0.255 & 199 & 2 \\
\hline & 54 & 3852 & 0.618 & 174 & 2 \\
\hline & Broken@12 & 15453 & 1.995 & 485 & 4 \\
\hline & Control & 15 & 0.520 & 177 & 4 \\
\hline \multicolumn{6}{|l|}{1987} \\
\hline & 06 & 4850 & 0.676 & 213 & 2 \\
\hline & 18 & 7350 & 0.494 & 327 & 2 \\
\hline & 36 & 8400 & 0.374 & 334 & 2 \\
\hline & 54 & 5054 & 0.556 & 371 & 3 \\
\hline & Broken@12 & 7010 & 0.430 & 416 & 1 \\
\hline & $\mathrm{C}$ & 0 & 0.373 & 335 & 2 \\
\hline \multicolumn{6}{|l|}{1988} \\
\hline & 06 & 1815 & 0.337 & 143 & 2 \\
\hline & 18 & 4355 & 0.273 & 250 & 2 \\
\hline & 36 & 8740 & 0.265 & 266 & 2 \\
\hline & 54 & 2160 & 0.284 & 316 & 2 \\
\hline & Broken@12 & 4680 & 0.269 & 251 & 2 \\
\hline & Control & 9 & 0.462 & 349 & 2 \\
\hline
\end{tabular}


Table A.9 Average Radioactive Isotope Concentration in Tree Lysimeter Sump Water (pCL/L).

By Year

$\begin{array}{rrrrr}\text { Year } & \text { Tr.29 } & \text { Sr-90 } & \text { H.3 } & \text { No. Obs } \\ 1985 & 520 & 1.012 & 91 & 35 \\ 1986 & 3523 & 0.498 & 347 & 13 \\ 1987 & 1682 & 0.655 & 434 & 6\end{array}$

By Treatment

$\begin{array}{lrrrr}\text { Treatment } & \text { Tc.92 } & \text { Sr-90 } & \text { H.3 } & \text { No.Obs } \\ 36 & 1478 & 1.034 & 256 & 17 \\ 54 & 1275 & 0.604 & 150 & 16 \\ \text { Broken@12 } & 2648 & 0.428 & 230 & 16 \\ \text { Control } & 16 & 0.300 & 121 & 7\end{array}$

By Year and Treatment

\begin{tabular}{|c|c|c|c|c|c|}
\hline Year & Treatment & Tc. 99 & Sr -90 & H.3 & No, Obs \\
\hline & 36 & 688 & 2.100 & 102 & 10 \\
\hline & 54 & 132 & 0.800 & 63 & 10 \\
\hline & Broken@12 & 9.40 & 0.500 & 132 & 10 \\
\hline & Control & 21 & 0.500 & 43 & 5 \\
\hline \multicolumn{6}{|l|}{1286} \\
\hline & 36 & 2713 & 0.862 & 438 & 4 \\
\hline & 54 & 3313 & 0.269 & 238 & 4 \\
\hline & Braken@12 & 5423 & 0.444 & 401 & 4 \\
\hline & Control & 6 & 0.174 & 212 & 1 \\
\hline \multicolumn{6}{|l|}{1287} \\
\hline & 36 & 945 & 0.639 & 492 & 2 \\
\hline & 54 & 2666 & 0.981 & 410 & 2 \\
\hline & Broken@12 & 2870 & 0.463 & 382 & 1 \\
\hline & Control & 1 & 0.226 & 419 & 1 \\
\hline \multicolumn{6}{|l|}{1988} \\
\hline & & 5510 & 0.384 & 594 & 1 \\
\hline & Broken@12 & 8410 & 0.184 & 379 & \\
\hline
\end{tabular}


Table A.10 Average Radioactive Isotope Concentration in Crop Lysimeter Sump Water ( $\mathrm{pCi} / \mathrm{L})$.

By Year

$\begin{array}{lrr}\text { Year } & \text { Tr.99 } & \text { Sr.20 } \\ 1985 & & \\ 1986 & 1717 & 3.625 \\ 1987 & 15923 & 5.974 \\ 1988 & 450 & 3.990 \\ & 2885 & 2.469\end{array}$

H.3 No. Obs

$58 \quad 25$

$464 \quad 16$

273

268

3

By Treatment

\section{Treatment}

Tr. 99

18

3910

Sr-90

3.335

36

7106

5.401

Broken@12

14970

7.918

Control

1.081

$\mathrm{H} \cdot 3 \mathrm{No} \mathrm{Obs}$

195

179

361

197

14

14

11

28

Tc.92

Sr-90

$\mathrm{H}-3 \mathrm{No} \mathrm{Obs}$

Year

Treatment

Te.92

1985

1986

18
36
Broken@12
Control

$$
1069
$$

1103

5321

2.300

7.867

1.800

10920

$\begin{array}{lr}36 & 19788 \\ \text { Broken@12 } & 32975 \\ \text { Control } & 8\end{array}$

$\begin{array}{lr}36 & 19788 \\ \text { Broken@12 } & 32975 \\ \text { Control } & 8\end{array}$

4.815

8.168

10.335

0.580

12

1987

18
36
Control

191

1110

48

2.360

7.710

1.900

$\begin{array}{ll}48 & 7 \\ 58 & 8 \\ 89 & 5 \\ 39 & 5\end{array}$

1288

$\begin{array}{lr}18 & 1689 \\ 36 & 10400 \\ \text { Broken@12 } & 3085\end{array}$

2.415

4.230

3.160

$\begin{array}{ll}479 & 4 \\ 342 & 4 \\ 796 & 4 \\ 241 & 4\end{array}$

120

327

372

1

181

2

348

169

1 

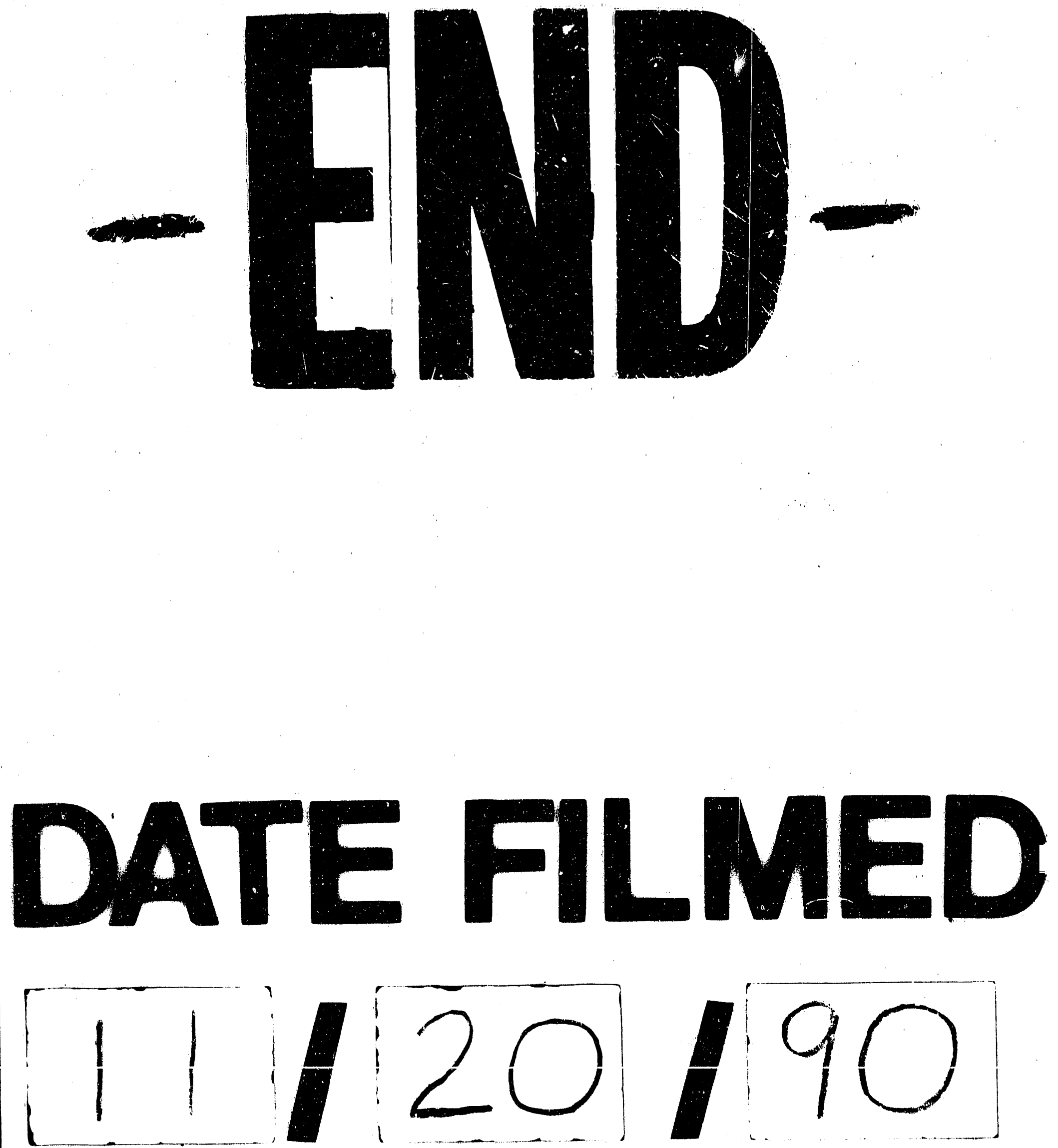
